\title{
SCALING RELATION BETWEEN EARTHQUAKE SIZE AND DURATION OF FAULTING FOR SHALLOW EARTHQUAKES IN SEISMIC MOMENT BETWEEN $10^{10}$ AND $10^{25}$ dyne $\cdot \mathrm{cm}$
}

\author{
Yoshihisa IIo \\ Regional Center for Earthquake Prediction, Faculty of Science, \\ Kyoto University, Kyoto, Japan
}

(Received July 16, 1985; Revised April 9, 1986)

The relation between earthquake size (radiated energy or seismic moment) and duration of faulting (predominant period or corner frequency) was investigated from a waveform analysis of shallow earthquakes with a seismic moment between $10^{10}$ and $10^{25}$ dyne $\cdot \mathrm{cm}$. The earthquakes analyzed were observed at relatively short focal distances where anelastic attenuation had no serious effect on their waveforms. The waveforms are characterized by their simplicity and relative lack of coda.

We found that the radiated energy of the $\mathrm{P}$ and $\mathrm{S}$ wave is proportional to the fifth power of the period of $\mathrm{P}$ and $\mathrm{S}$ wave velocity seismograms, respectively, and that the relation between the seismic moment $\left(M_{0}\right)$ and the corner frequency of the $\mathrm{P}$ wave $\left(f_{0}\right)$ is given by $M_{0} \propto f_{0}^{-4}$. The above two relations are consistent with each other. The relation $M_{0} \propto f_{0}{ }^{-3}$ which is generally accepted for large earthquakes $\left(M_{0}>10^{25}\right.$ dyne $\left.\cdot \mathrm{cm}\right)$ does not hold true for smaller earthquakes $\left(M_{0}<10^{25}\right.$ dyne $\cdot \mathrm{cm}$ ), possibly because, for smaller earthquakes, slip velocity does not exceed a critical level owing to small rupture velocity and because effective stress is not constant and independent of seismic moment.

The relation between $M_{0}$ and the fault length $(L)$ was estimated as $M_{0} \propto L^{2.5} \sim L^{3.2}$ from aftershock distributions ranging from a microearthquake to moderate earthquakes. By combining this relation with the $M_{0}-f_{0}$ relation, we have come to the conclusion that average rupture velocity and slip velocity decrease with the decreasing seismic moment. We have also concluded that the deviations of data from the relation $M_{0} \propto f_{0}^{-3}$ are not attributed to small stress drop but small rupture velocity and slip velocity.

\section{Introduction}

We will investigate the relations between radiated energy and the predominant period, and the seismic moment $\left(M_{0}\right)$ and the corner frequency of the $\mathrm{P}$ wave spectrum $\left(f_{0}\right)$ by analyzing seismograms. The seismograms used in this paper were obtained in the observations of several earthquake sequences that occurred in and near Japan in recent years. Seismic moments of the earthquakes studied in this paper range widely from $10^{10}$ to $10^{25} \mathrm{dyne} \cdot \mathrm{cm}$. 
Furthermore, we will investigate the relation between $M_{0}$ and the fault length $(L)$; we will make clear scaling relations between earthquake source parameters. On the basis of these relations, we will discuss the problem of what determines earthquake size.

Since AKI (1967) had proposed a scaling law of seismic spectrum, many investigators dealt with scalings of seismic spectrum and source time function or source parameters (e.g., AKI, 1972; KANAMORI and ANDERSON, 1975; GELLER, 1976). They reached the following conclusions for large shallow earthquakes $\left(M_{0}>10^{25}\right.$ dyne $\cdot \mathrm{cm})$ : The similarity law $(W \propto L ; D \propto L)$ is recognized between the static source parameters of the fault length $(L)$, the fault width $(W)$, and the average dislocation $(D)$; The dynamic source parameters of the average rupture velocity $\left(V_{\mathrm{r}}\right)$ and the average slip velocity $(\dot{D})$ have a constant value independent of earthquake size. Furthermore, the following was derived from the above conclusions: The stress drop $(\Delta \sigma)$ has a constant value independent of earthquake size; Seismic moment is inversely proportional to the cube of corner frequency of the seismic spectrum (from now on, we will call this relation "the cube law").

On the other hand, for earthquakes of which $M_{0}<10^{25}$ dyne $\cdot \mathrm{cm}$, the scaling of seismic spectrum was investigated mainly by teleseismic determinations of body wave spectra interpreted by the method of BRUNE $(1970,1971)$ (e.g., THATCHER, 1972; TUCKER and Brune, 1973; Thatcher and HANKs, 1973; MAlion and Long, 1980; Fletcher, 1980; ARCHUleta et al., 1982; HAAR et al., 1984) or the coda method developed by AKI and CHOUET (1975) (e.g., Chouet et al., 1978; RAUTIAN et al., 1978). By combining the results of several studies for mainly small to moderate shallow earthquakes in the Southern California Region $\left(10^{18}<M_{0}<\right.$ $10^{27}$ dyne $\cdot \mathrm{cm}$ ), HaNKs (1977) indicated that $\Delta \sigma$ ranges from about 1 to 100 bars independent of earthquake size. Since the $\Delta \sigma$ of large earthquakes ranges from 10 to 100 bars (KANAMORI and ANDERSON, 1975), we have inferred from the data compiled by HANKS (1977) that the average stress drop of small to moderate earthquakes is smaller than that of large earthquakes. CHOUET et al. (1978) showed that below a certain seismic moment, the corner frequency is lower than that indicated by the cube law, for earthquakes in various regions $\left(10^{17}<M_{0}<10^{26}\right.$ dyne $\cdot \mathrm{cm}$ ). Rautian et al. (1978) showed that the stress drop decreases with the decreasing seismic moment for earthquakes in the Pamir and South Tien Shan region $\left(10^{17}<M_{0}<10^{25}\right.$ dyne $\left.\cdot \mathrm{cm}\right)$. Several studies also obtained similar results (e.g., FLETCHER (1980) for the Oroville California aftershocks $\left(10^{16}<M_{0}<10^{19}\right.$ dyne $\mathrm{cm}$ ); FRANKEL (1981) for the swarm earthquakes in the northeastern Caribbean $\left(10^{18}<M_{0}<10^{20}\right.$ dyne $\left.\cdot \mathrm{cm}\right)$; ARCHULETA et al. (1982) for the Mammoth Lake, California sequence $\left(10^{19}<M_{0}<10^{24} \mathrm{dyne} \cdot \mathrm{cm}\right)$; HAAR et al. (1984) for the Arkansas swarm $\left.\left(10^{18}<M_{0}<10^{22} \mathrm{dyne} \cdot \mathrm{cm}\right)\right)$. Moreover, MALION and LonG (1980) determined body wave spectra of microearthquakes $\left(10^{13}<M_{0}<10^{18}\right.$ dyne $\cdot \mathrm{cm}$ ) and showed that $\Delta \sigma$ ranges from less than 0.001 bar to an upper limit of about 2 bars. These values of $\Delta \sigma$ are much smaller than that for large earthquakes. 
The above studies for earthquakes of which $10^{13}<M_{0}<10^{25}$ dyne $\cdot \mathrm{cm}$ showed $\Delta \sigma$ has a tendency to decrease with the decreasing seismic moment. Since the method by BRUNE $(1970,1971)$ calculated the fault radius $(r)$ from $f_{0}$ by using the relation $r \propto 1 / f_{0}$, under the assumption of constant rupture velocity (see Appendix 3 ), the above studies showed that corner frequencies of earthquakes $\left(M_{0}<10^{25}\right.$ dyne $\left.\cdot \mathrm{cm}\right)$ are lower than those indicated by the cube law and that the deviations from the cube law have a tendency to increase with the decreasing seismic moment. However, the magnitude range in seismic moment of each analysis is narrow. Consequently, the scaling law of earthquakes of which $M_{0}<10^{25}$ dyne $\cdot \mathrm{cm}$ is not completely established.

In this paper, the seismograms of earthquakes of which seismic moments range very widely from $10^{10}$ to $10^{25}$ dyne $\cdot \mathrm{cm}$ were analyzed by one and the same method. Therefore, the scaling relation between earthquake size and duration of faulting for earthquakes of which $M_{0}<10^{25}$ dyne $\cdot \mathrm{cm}$ was made clear.

The reason the seismic events analyzed in this paper cover the remarkably wide range in seismic moment by a factor of fifteen orders is that the microfractures in the Nakatatsu mine of which $10^{10}<M_{0}<10^{12}$ dyne $\cdot \mathrm{cm}$ (Iro, $1984 \mathrm{a}, \mathrm{b}$ ) are used in the analysis. Since these microfractures are regarded as induced earthquakes (IIo, 1984 a), they are treated in the same manner as earthquakes.

By the way, in recent years, since telemetered array systems for microearthquake observation began operation, precise hypocentral distributions of aftershocks of small earthquakes were able to be made. Furthermore, the aftershock distribution of the microfracture accompanied with aftershocks in the Nakatatsu mine was investigated (IIo, 1984 b). The fault length of earthquakes from which $M_{0}<10^{25}$ dyne $\cdot \mathrm{cm}$ was determined without assuming rupture velocity. We will discuss the scaling relation between various kinds of source parameters of earthquakes from which $M_{0}<10^{25} \mathrm{dyne} \cdot \mathrm{cm}$.

\section{Data}

Outlines of the earthquake sequences used in this analysis and the observation systems are shown in Tables 1 and 2, respectively. Details of some sequences are described in the references.

From Table 1, we find that smaller earthquakes were observed at shorter focal distances than larger ones. All the seismograms analyzed were scarcely distorted by anelastic attenuation through the paths between the sources to the receivers as described in a later section. In particular, these seismograms were not distorted in alluvial layers near the ground surface, because microearthquakes to small earthquakes were observed in tunnels excavated in rocks except for the aftershocks of the 1984 Western Nagano Prefecture earthquake (from now on, we will abbreviate these to "the Nagano aftershocks"). The Nagano aftershocks were observed at the bed rock of a large road cut.

The observation systems used will be introduced simply as follows. These 
Table 1. Outlines of earthquake sequences.

\begin{tabular}{|c|c|c|c|c|c|}
\hline Region & Station & $M$ & $M_{0}($ dyne $\cdot \mathrm{cm})$ & $\begin{array}{l}\text { Distance } \\
(\mathrm{km})\end{array}$ & $\begin{array}{l}\text { Depth } \\
(\mathrm{km})\end{array}$ \\
\hline Nihonkai-chubu & Fukaura & $3.8-7.1$ & $2.5 \times 10^{21}-5.6 \times 10^{24}$ & $56-120$ & $-20^{1)}$ \\
\hline E off Izu Pen. & Yugashima & $2.7-3.9$ & $4.1 \times 10^{19}-2.1 \times 10^{21}$ & $30-37$ & $11-18^{21}$ \\
\hline Near Abuyama & Abuyama & $-0.9-4.2$ & $1.5 \times 10^{16}-6.2 \times 10^{20}$ & $3.8-39$ & $6-15^{31}$ \\
\hline West Nagano & Uguigawa & $-2.7--0.1$ & $2.4 \times 10^{14}-5.3 \times 10^{16}$ & $0.38-5.5$ & $<5$ \\
\hline $\begin{array}{l}\text { Nakatatsu } \\
\text { (earthquake) }\end{array}$ & Nakatatsu & $-0.3-0.6$ & $9.0 \times 10^{15}-7.5 \times 10^{16}$ & $11-12$ & \\
\hline $\begin{array}{l}\text { Nakatatsu } \\
\quad \text { (microfracture) }^{*}\end{array}$ & Nakatatsu & & $5.4 \times 10^{10}-9.9 \times 10^{11}$ & $0.013-0.014$ & -0.7 \\
\hline
\end{tabular}

Nihonkai-chubu, the aftershocks of the 1983 Nihonkai-Chubu earthquake; E off Izu Pen., the 1983 Izu Toho-oki swarm earthquakes; Near Abuyama, the earthquakes near Abuyama; West Nagano, the aftershocks of the 1984 Western Nagano Prefecture earthquake; Nakatatsu (earthquake), the earthquakes near the Nakatatsu mine; Nakatatsu (microfracture), the microfractures induced by an explosion in the Nakatatsu mine. * Microfracture induced by an explosion.

${ }^{1)}$ SATo (1984), 2) J.M.A., ${ }^{3)}$ routine processing of the telemetered array system for microearthquake observation at Abuyama Seismological Observatory.

Table 2. Outlines of observation systems.

\begin{tabular}{|c|c|c|c|c|}
\hline Station & Seismometer & $\begin{array}{l}\text { Sensitivity } \\
\text { (V/kine) }\end{array}$ & $\begin{array}{l}\text { Frequency } \\
\text { range } \\
(\mathrm{Hz})\end{array}$ & Reference \\
\hline Fukaura & $\begin{array}{l}\text { Velocity-type } \\
\text { strongmotion }\end{array}$ & $0.5,5.0$ & $0.05-20$ & UMEDA et al. (1984) \\
\hline Yugashima & Katsujima $1 \mathrm{~Hz}$ & 33 & $1-50$ & $\begin{array}{l}\text { FACULTY OF SCIENCE, } \\
\text { KYOTO UNIVERSITY } \\
(1983)\end{array}$ \\
\hline Abuyama & $\begin{array}{l}\text { L-22D } \\
\text { Katsujima } 1 \mathrm{~Hz}\end{array}$ & $\begin{array}{l}3.0,30,60 \\
600,6,000\end{array}$ & $2-300$ & \\
\hline Uguigawa & $\mathrm{L}-22 \mathrm{D}$ & $\begin{array}{c}190,600 \\
6,100\end{array}$ & $2-270$ & IIO (1985) \\
\hline $\begin{array}{l}\text { Nakatatsu } \\
\text { (earthquake) }\end{array}$ & L-22D & 6,500 & $2-600$ & Iro (1984a) \\
\hline $\begin{array}{l}\text { Nakatatsu } \\
\text { (microfracture) }\end{array}$ & bbn $507^{*}$ & $96,910^{*}$ & $2-10,000$ & Iro (1984a) \\
\hline
\end{tabular}

Frequency range indicates the range of flat response $(-3 \mathrm{~dB})$ to ground velocity.

* Accelerometer $(\mathrm{V} / \mathrm{g}),{ }^{* *}$ microfracture induced by an explosion.

systems have the nearly same construction. The seismometers are of the velocity type. Microearthquakes were observed mainly with a seismometer (L-22D) in which the characteristic frequency is $2.2 \mathrm{~Hz}$. This seismometer has a wide frequency range of flat response to ground velocity ranging from about 2 to $1,000 \mathrm{~Hz}$. Only the 
$2 \mathrm{~cm} / \mathrm{s}$

6/21 $15: 25 \quad M=7.1$

a

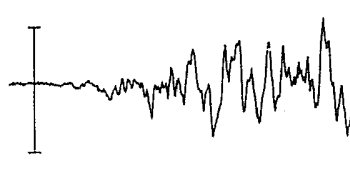

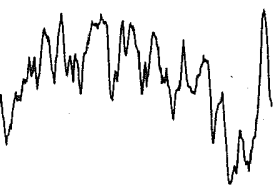

4 see

$8 \times 10^{-3} \mathrm{~cm} / \mathrm{s}$

$1 / 17 \quad 23: 26 \quad M=3.7$

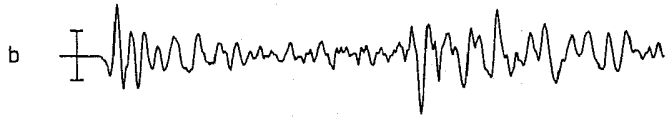

$2 \mathrm{sec}$

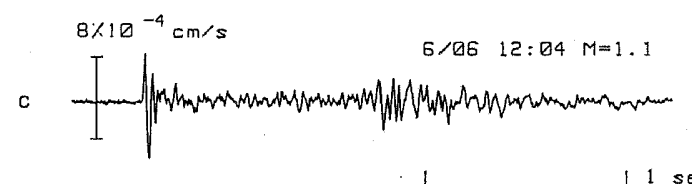

$1 \sec$

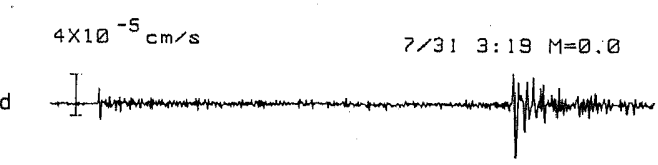

$0.5 \sec$

$4 \times 10^{-5} \mathrm{~cm} / \mathrm{s} \quad 9 / 18 \quad 17: 34: 41 \quad M=-2.5$

e

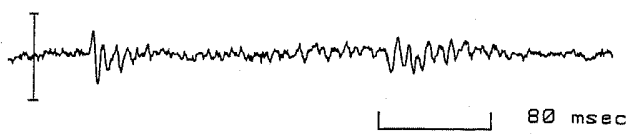

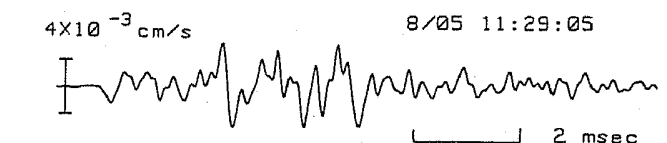

Fig. 1. Examples of velocity seismograms in the vertical component. (a) The largest aftershock of the 1983 Nihonkai-chubu earthquake. (b) 1983 East off Izu Peninsula swarm earthquake. (c) Earthquake near Abuyama. (d) Earthquake near the Nakatatsu mine. (e) Aftershock of the 1984 Western Nagano Prefecture earthquake. (f) Microfracture induced by an explosion in the Nakatatsu mine.

microfractures induced by an explosion in the Nakatatsu mine were observed with accelerometers. The outputs of seismometers were amplified by several magnifications and recorded on different channels of an analog data recorder with the trigger method. The Nagano aftershocks and the microfractures in the Nakatatsu 

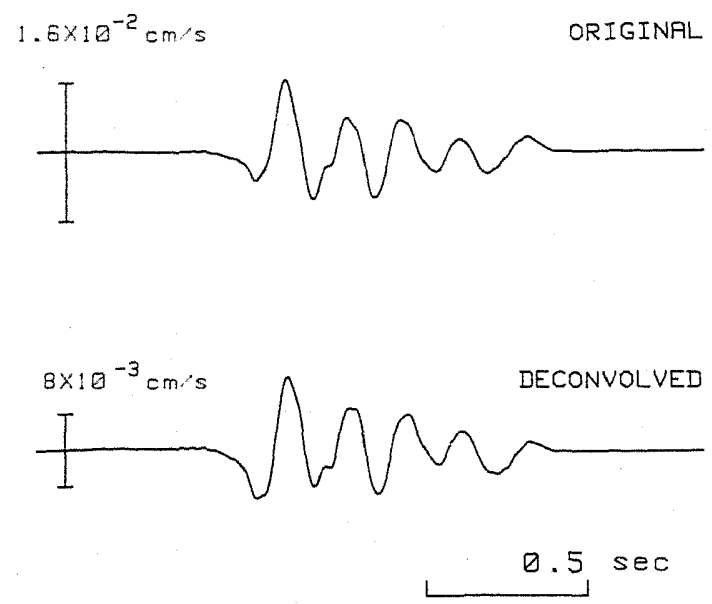

Fig. 2. Comparison between the original seismogram and the ground velocity calculated by the deconvolution of the instrument response for 1983 East off Izu Peninsula swarm earthquake. Only initial parts of $P$ waves are shown.

mine were recorded continuously on an analog data recorder, because the frequencies of their signals were too high to delay with memory devices. Since the sensitivities to ground velocity had some different values for an individual system as listed in Table 2, earthquakes over the wide range of magnitude were recorded with a large signal-noise ratio without clipping. The frequency ranges of flat responses of the systems are also listed in Table 2 . The frequency range of each system is much wider than that of seismic ground motions from each earthquake sequence. Furthermore, 50 or $60 \mathrm{~Hz}$ contamination was scarcely detected.

Examples of velocity seismograms in the vertical component are shown in Fig. 1. These $P$ waveforms are remarkable in their simplicity and relative lack of coda, except for Fig. $1 \mathrm{a}$, the largest aftershock of the 1983 Nihonkai-chubu earthquake $M=7.1$ (from now on, we will abbreviate this to "the Nihonkai-chubu largest aftershock"). Almost all the seismograms analyzed in this paper have such a simple waveform as shown in Fig. 1 and their first or second half cycle gives the maximum amplitude of $\mathrm{P}$ waves, while the velocity seismograms of large earthquakes in which $M_{0}>10^{25}$ dyne $\cdot \mathrm{cm}$ have a complex waveform. The simplicity of the $\mathrm{P}$ waveforms proves that the seismograms analyzed have not been seriously contaminated by near-site scattering and are suitable for waveform analysis.

The seismograms analyzed represent seismic ground motions exactly, because the frequency ranges of flat responses from the observation systems are sufficiently wider than those of seismic ground motions. Except for the 1983 East off Izu Peninsula swarm earthquakes, the characteristic frequency of the seismometer $(1 \mathrm{~Hz})$ is not sufficiently lower than the predominant frequencies of seismic ground motions (about $5 \mathrm{~Hz}$ ). For this reason, the ground motions were calculated from the original seismogram by the deconvolution of the instrument response and com- 
pared with the original seismogram as shown in Fig. 2. The double amplitude of the first cycle of the original seismogram is only about $15 \%$ smaller than that of the calculated ground motion. We disregarded the difference between the original seismogram and the ground motion. In Fig. 1, the time scale drawn under each trace varies widely from $4 \mathrm{~s}$ to $2 \mathrm{~ms}$ by a factor of 2,000. This clearly shows that the scaling relation investigated in this paper covers a surprisingly wide range.

\section{Relation between Radiated Energy or Seismic Moment and Duration of Faulting}

\subsection{Relation between radiated energy and predominant period}

3.1.1 Relation between radiated energy and the predominant period of the $P$ wave

We will now investigate the relation between radiated energy and the predominant period of the $\mathrm{P}$ wave. Radiated energy of the $\mathrm{P}$ waves was obtained by the following method. The double amplitude $A_{\mathrm{P}}$ and the period $t_{\mathrm{P}}$ of the first cycle of a velocity seismogram of $\mathrm{P}$ waves in the vertical component were measured as shown in Fig. 3a. $A_{\mathrm{P}}$ was corrected for the effect of anelastic attenuation. The corrected double amplitude $A_{\mathrm{P}}{ }^{*}$ was calculated by using the equation

$$
A_{\mathrm{P}}{ }^{*}=A_{\mathrm{P}} \cdot \exp \left(\pi R / Q_{\mathrm{P}} V_{\mathrm{P}} t_{\mathrm{P}}\right)
$$

where $R$ is the focal distance, $V_{\mathrm{P}}$ is the average $\mathrm{P}$ wave velocity between source and receiver and $Q_{\mathrm{P}}$ is the $Q$ for the $\mathrm{P}$ wave. $V_{\mathrm{P}}$ was set to be $6 \mathrm{~km} / \mathrm{s}$, except for the $V_{\mathrm{P}}$ in the Nakatatsu mine, which at $6.3 \mathrm{~km} / \mathrm{s}$ was measured in the observation of an explosion in the mine (IIo, 1984a). $Q_{\mathbf{P}}$ was taken to be 500 . However, with the microfractures induced by an explosion, the effect of anelastic attenuation was disregarded because their focal distances were very short, about four times as long as their wave lengths. Finally, the radiated energy of $\mathrm{P}$ wave $\left(E_{\mathrm{P}}\right)$ was estimated by using the equation

$$
E_{\mathrm{P}}=(1 / 2) 4 \pi R^{2} \rho v_{\mathrm{p}} t_{\mathrm{P}}\left(A_{\mathrm{P}} * / 2 F R_{\theta \varphi}\right)^{2}
$$

where $\rho$ is the density $\left(2.7 \mathrm{~g} / \mathrm{cm}^{3}\right), v_{\mathrm{P}}$ is the near-site $P$ wave velocity $(4 \mathrm{~km} / \mathrm{s})$ and $F$ is the free-surface correction (a factor of 2). The $v_{\mathrm{P}}$ in the Nakatatsu mine was determined to be $6.3 \mathrm{~km} / \mathrm{s}$. The correction for radiation pattern $R_{\theta \varphi}$ was assumed to be 0.4 following MALION and LONG (1980). The microearthquakes observed in the Nakatatsu mine were not corrected for the effect of free surface because the depth of the observation site $(700 \mathrm{~m})$ was much larger than the wave lengths of these microearthquakes. The microfracture accompanied with aftershocks was also not corrected because its wave length was longer than the diameter of tunnels where the seismometers were settled, while the microfractures induced by an explosion were corrected because their wave lengths were shorter than the diameters of the tunnels.

We deduced from Fig. 3 that $t_{\mathrm{P}}$ is equal to the duration of faulting which is calculated by $L / 2 V_{\mathrm{r}}$ for the circular fault. Figure 3 shows the initial part of the displacement seismogram is a pulse with a simple shape and that the $t_{\mathrm{p}}$ is nearly 

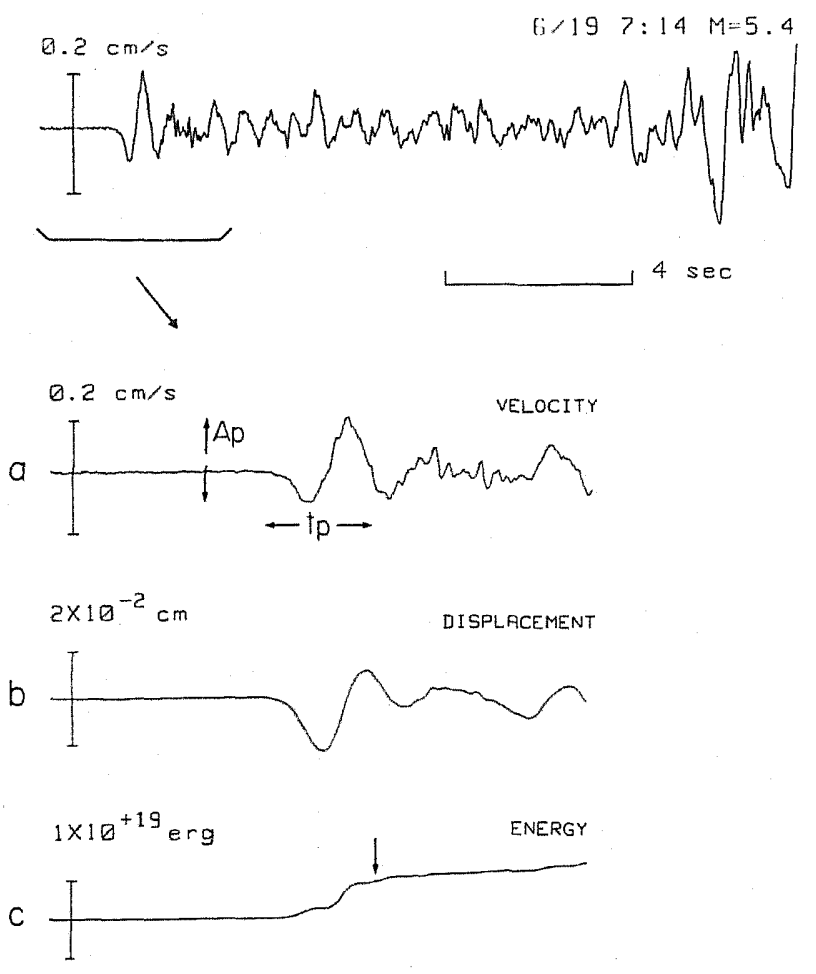

$1 \sec$

Fig. 3. Measurement of $A_{\mathrm{P}}$ and $t_{\mathrm{P}}$ and comparison between three kinds of traces. (a) Velocity waveform. (b) Integrated displacement waveform. (c) Cumulative curve of seismic energy. The arrow in $\mathrm{c}$ indicates the time that is $\mathrm{P}$-arrival plus the period $t_{\mathrm{p}} . t_{\mathrm{P}}$ is nearly equal to the pulse width of the displacement waveform.

equal to this pulse width. Sato and Hirasawa (1973) pointed out that the width of the displacement $\mathbf{P}$ pulse is nearly equal to the duration of faulting calculated by $L / 2 V_{\mathrm{r}}$ for the circular fault. Following BOATwRIGHT (1980), although the duration of faulting is calculated by $L / V_{\mathrm{r}}$ because of the consideration of the healing stage, the relation between $t_{\mathrm{P}}$ and the duration of faulting is the same.

Since the duration of faulting is equal to $t_{\mathrm{P}}$, radiated energy of the $\mathrm{P}$ wave should be calculated by using part of a seismogram only for the period $t_{\mathrm{P}}$ after the onset of $\mathrm{P}$ waves. The seismic energy $E_{0}$ for the period $t$ after the onset of the $\mathrm{P}$ wave is calculated by using the equation

$$
E_{0}=\int_{0}^{t} 4 \pi R^{2} \rho\left(v / F R_{\theta \varphi}\right)^{2} \mathrm{~d} t
$$

where $v$ is the ground velocity. Therefore, when $t=t_{\mathrm{P}}$, the seismic energy $E_{0}$ is equal to the radiated energy of the $\mathrm{P}$ wave if the effect of anelastic attenuation can be 


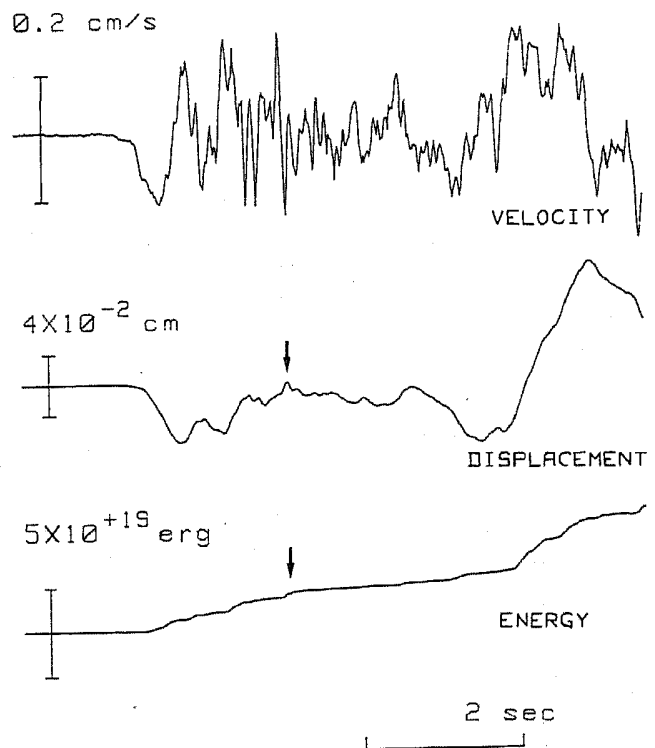

Fig. 4. Three kinds of traces of the aftershock of the 1984 Nihonkai-chubu earthquake $M=6.1$ (the second largest Nihonkai-chubu aftershock). The arrows indicate the time, that is $\mathrm{P}$-arrival plus the period $t_{\mathrm{P}}$.

disregarded. Figure $3 \mathrm{c}$ shows the change in $E_{0}$ against $t$ for the seismogram of Fig. $3 \mathrm{a}$. The arrow indicates the time which is the $\mathrm{P}$-arrival time plus the period $t_{\mathrm{p}}$. The $E_{0}$ at this time is $4.6 \times 10^{18} \mathrm{erg}$. On the other hand, the radiated energy $\left(E_{\mathrm{p}}\right)$ estimated by using Eq. (2) is the seismic energy calculated for the approximate sine wave with the same $A_{\mathrm{P}}$ and $t_{\mathrm{P}}$ as the first cycle of the $\mathrm{P}$ wave velocity seismogram. That for the seismogram in Fig. 3 a is $6.7 \times 10^{18} \mathrm{erg}$. We find that this almost agrees with the $E_{0}$ at the time which is the $\mathrm{P}$-arrival time plus the period $t_{\mathrm{P}}\left(4.6 \times 10^{18} \mathrm{erg}\right)$, taking into account the correction for anelastic attenuation (a factor of $(1.3)^{2}$ ). Therefore, we estimated the radiated energy of the $\mathrm{P}$ wave by using Eq. (2).

As mentioned in section 2, the velocity seismogram of which $M_{0}>10^{25}$ dyne $\mathrm{cm}$ has a complex waveform. As an example, the seismograms of the aftershock of the 1983 Nihonkai-chubu earthquake on June $9 M=6.1$ (from now on, we will call this "the second largest Nihonkai-chubu aftershock") are shown in Fig. 4. This velocity waveform is too complex to measure $A_{\mathrm{P}}$ and $t_{\mathrm{P}}$ directly on the seismogram. However, the displacement $P$ pulse has a simple shape. As shown in Fig. 4, the pulse width of the integrated displacement seismogram was regarded as $t_{\mathrm{p}}$ and the radiated energy was calculated by Eq. (3) setting $t$ to be $t_{\mathrm{p}}$. For the largest Nihonkai-chubu aftershock, $E_{\mathrm{P}}$ and $t_{\mathrm{P}}$ were also obtained in the same manner.

In the case of the microfracture accompanied by aftershocks, since its 
Table 3. Earthquake source data.

\begin{tabular}{|c|c|c|c|c|c|c|c|c|c|c|}
\hline No. & Date & Time & $M$ & $\begin{array}{l}t_{\mathrm{P}} \\
(\mathrm{s})\end{array}$ & $\begin{array}{c}E_{\mathrm{P}} \\
\text { (erg) }\end{array}$ & $\begin{array}{l}t_{\mathrm{s}} \\
(\mathrm{s})\end{array}$ & $\begin{array}{c}E_{\mathrm{S}} \\
\text { (erg) }\end{array}$ & $\begin{array}{c}f_{0} \\
(\mathrm{~Hz})\end{array}$ & $\begin{array}{c}M_{0} \\
(\text { dyne } \cdot \mathrm{cm})\end{array}$ & $\begin{array}{c}\sigma_{\mathrm{A}} \\
\text { (bars) }\end{array}$ \\
\hline \multicolumn{11}{|c|}{ Mid Japan Sea } \\
\hline 1 & 198361 & $21: 05$ & 3.8 & 0.17 & $1.3 \times 10^{16}$ & 0.40 & $3.1 \times 10^{16}$ & 5.3 & $2.9 \times 10^{21}$ & 5.3 \\
\hline 2 & 1 & $22: 01$ & 3.9 & 0.18 & $1.6 \times 10^{17}$ & 0.37 & $1.2 \times 10^{17}$ & 4.9 & $5.3 \times 10^{21}$ & 18 \\
\hline 3 & 2 & $3: 27$ & 3.8 & 0.31 & $7.4 \times 10^{16}$ & 0.36 & $6.7 \times 10^{17}$ & 2.5 & $2.1 \times 10^{22}$ & 13 \\
\hline 4 & 2 & $13: 12$ & 3.9 & 0.18 & $7.5 \times 10^{15}$ & 0.32 & $3.6 \times 10^{17}$ & 6.8 & $2.5 \times 10^{21}$ & 51 \\
\hline 5 & 2 & $14: 31$ & 4.2 & 0.25 & $3.3 \times 10^{16}$ & 0.32 & $2.9 \times 10^{17}$ & 3.4 & $7.0 \times 10^{21}$ & 16 \\
\hline 6 & 3 & $16: 23$ & 4.3 & 0.26 & $1.8 \times 10^{16}$ & 0.44 & $1.9 \times 10^{17}$ & 4.9 & $3.9 \times 10^{21}$ & 18 \\
\hline 7 & 4 & $3: 04$ & 4.2 & 0.46 & $1.8 \times 10^{17}$ & 0.44 & $1.8 \times 10^{18}$ & 1.8 & $4.4 \times 10^{22}$ & 15 \\
\hline 8 & 5 & $0: 57$ & 3.7 & 0.13 & $6.0 \times 10^{16}$ & 0.16 & $2.4 \times 10^{17}$ & 5.4 & $2.9 \times 10^{21}$ & 36 \\
\hline 9 & 6 & $7: 30$ & 3.4 & 0.48 & $1.0 \times 10^{15}$ & 0.54 & $6.6 \times 10^{16}$ & 2.4 & $1.1 \times 10^{22}$ & 2.1 \\
\hline 10 & 6 & $16: 04$ & 4.4 & 0.46 & $1.4 \times 10^{17}$ & 0.42 & $5.0 \times 10^{17}$ & 1.8 & $3.6 \times 10^{22}$ & 6.2 \\
\hline 11 & 7 & $15: 06$ & 3.9 & 0.17 & $1.1 \times 10^{17}$ & 0.28 & $1.4 \times 10^{17}$ & 7.8 & $5.1 \times 10^{21}$ & 20 \\
\hline 12 & 9 & $13: 37$ & 5.1 & 0.84 & $2.4 \times 10^{18}$ & 0.72 & $1.6 \times 10^{19}$ & 1.2 & $3.3 \times 10^{23}$ & 19 \\
\hline 13 & 9 & $21: 49$ & 6.1 & 2.23 & $2.1 \times 10^{19}$ & 1.32 & $3.4 \times 10^{21}$ & 0.37 & $5.6 \times 10^{24}$ & 210 \\
\hline 14 & 10 & $16: 20$ & 5.0 & 0.86 & $6.6 \times 10^{16}$ & 1.00 & $5.7 \times 10^{18}$ & 1.4 & $4.5 \times 10^{22}$ & 45 \\
\hline 15 & 11 & $15: 15$ & 4.9 & 0.64 & $3.2 \times 10^{17}$ & 0.72 & $1.6 \times 10^{18}$ & 1.7 & $9.2 \times 10^{22}$ & 7.4 \\
\hline 16 & 19 & $7: 14$ & 5.4 & 0.86 & $6.7 \times 10^{18}$ & 0.90 & $7.9 \times 10^{19}$ & 1.7 & $4.0 \times 10^{23}$ & 49 \\
\hline 17 & 20 & $11: 43$ & 4.6 & 0.94 & $1.4 \times 10^{18}$ & 1.24 & $1.3 \times 10^{19}$ & 0.98 & $2.5 \times 10^{23}$ & 20 \\
\hline 18 & 21 & $15: 25$ & 7.1 & 9.19 & $2.3 \times 10^{21}$ & & & & & \\
\hline 19 & 21 & $16: 40$ & 4.2 & 0.44 & $1.3 \times 10^{17}$ & 0.52 & $3.3 \times 10^{18}$ & 2.4 & $4.2 \times 10^{22}$ & 29 \\
\hline 20 & 21 & $18: 13$ & 4.8 & 0.66 & $2.1 \times 10^{17}$ & 0.78 & $1.2 \times 10^{19}$ & 1.6 & $7.1 \times 10^{22}$ & 59 \\
\hline 21 & 22 & $0: 2$ & 4.8 & 0.76 & $2.9 \times 10^{17}$ & 1.02 & $4.3 \times 10^{18}$ & 1.2 & $1.7 \times 10^{23}$ & 9.3 \\
\hline 22 & 22 & $1: 22$ & 4.2 & 0.60 & $2.1 \times 10^{17}$ & 0.56 & $6.8 \times 10^{18}$ & 1.9 & $5.4 \times 10^{22}$ & 46 \\
\hline 23 & 22 & $13: 34$ & 5.3 & 0.82 & $1.0 \times 10^{18}$ & 0.67 & $9.2 \times 10^{18}$ & 1.3 & $1.9 \times 10^{23}$ & 19 \\
\hline 24 & 22 & $14: 40$ & 5.0 & 0.50 & $2.0 \times 10^{17}$ & 0.70 & $9.2 \times 10^{18}$ & 1.2 & $8.5 \times 10^{22}$ & 39 \\
\hline 25 & 24 & $11: 10$ & 4.3 & 0.44 & $3.0 \times 10^{16}$ & 0.44 & $3.3 \times 10^{17}$ & 2.5 & $1.2 \times 10^{22}$ & 11 \\
\hline 26 & 26 & $3: 40$ & 4.2 & 0.82 & $7.9 \times 10^{16}$ & 0.72 & $9.8 \times 10^{18}$ & 0.73 & $9.4 \times 10^{22}$ & 36 \\
\hline 27 & 26 & $22: 57$ & 5.0 & 0.58 & $3.5 \times 10^{17}$ & 0.76 & $1.1 \times 10^{19}$ & 1.2 & $1.3 \times 10^{23}$ & 31 \\
\hline 28 & 29 & $14: 11$ & 5.0 & 0.74 & $7.8 \times 10^{17}$ & 1.06 & $2.9 \times 10^{18}$ & 1.2 & $1.4 \times 10^{23}$ & 9.2 \\
\hline
\end{tabular}




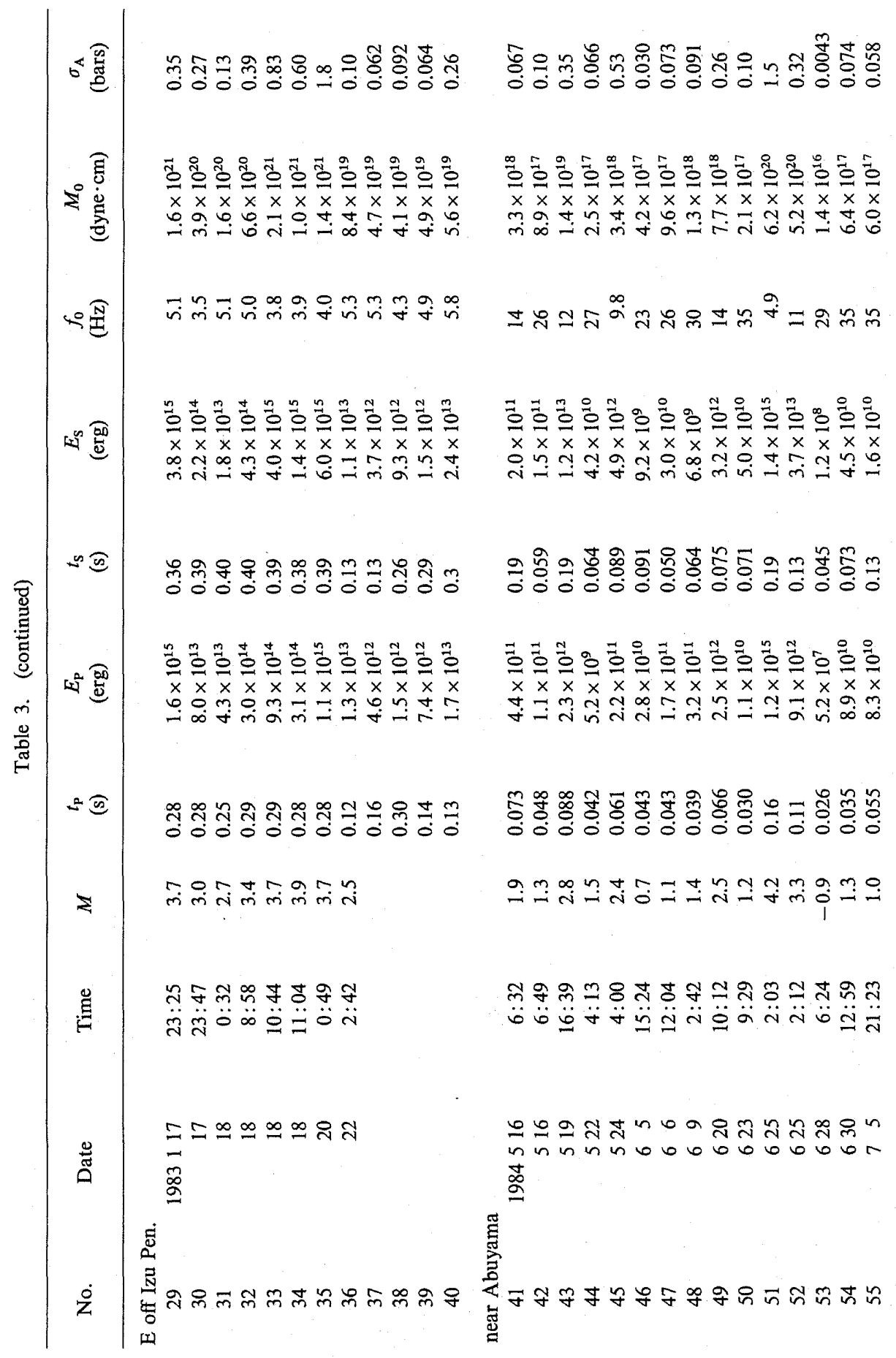




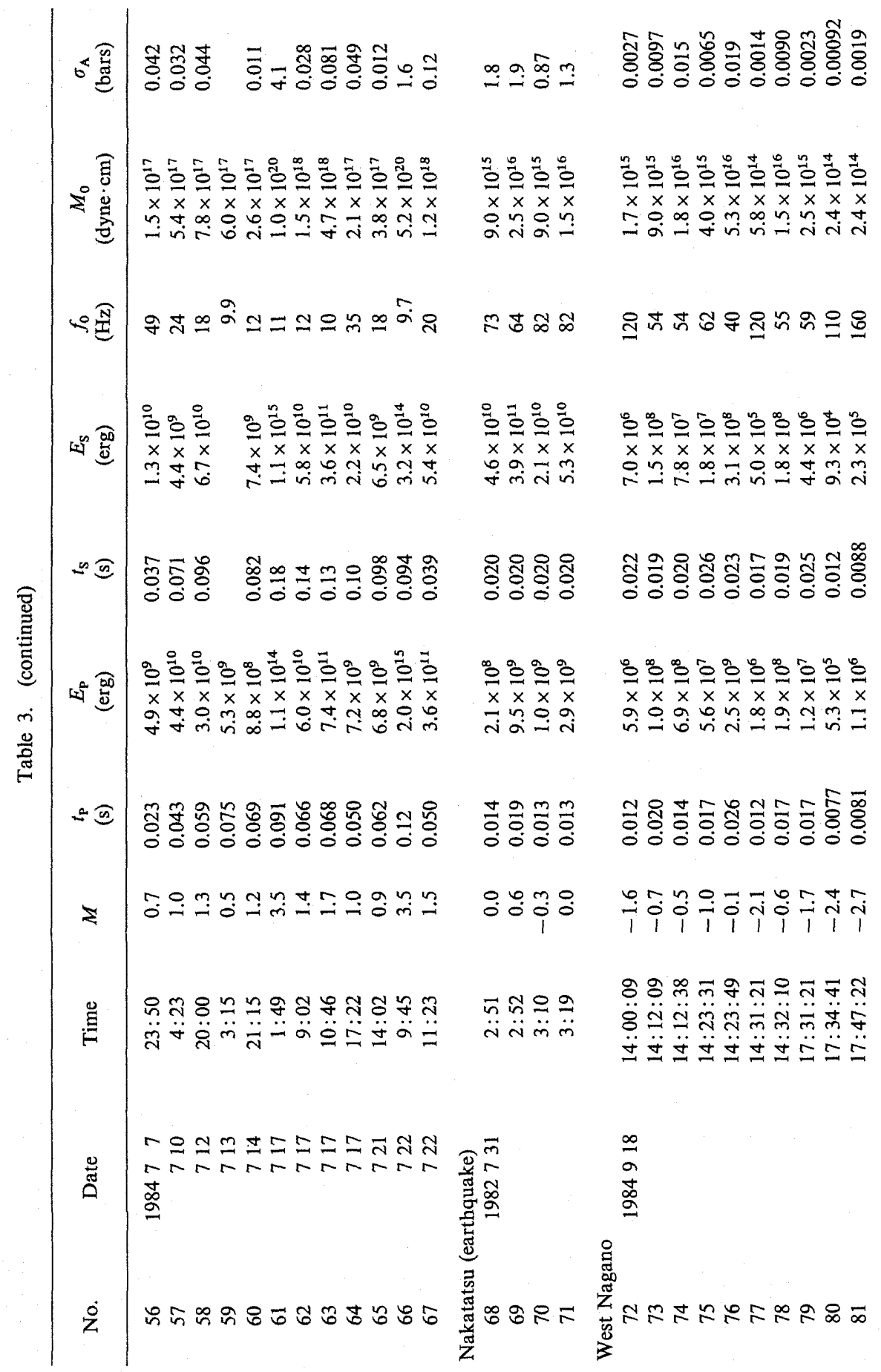




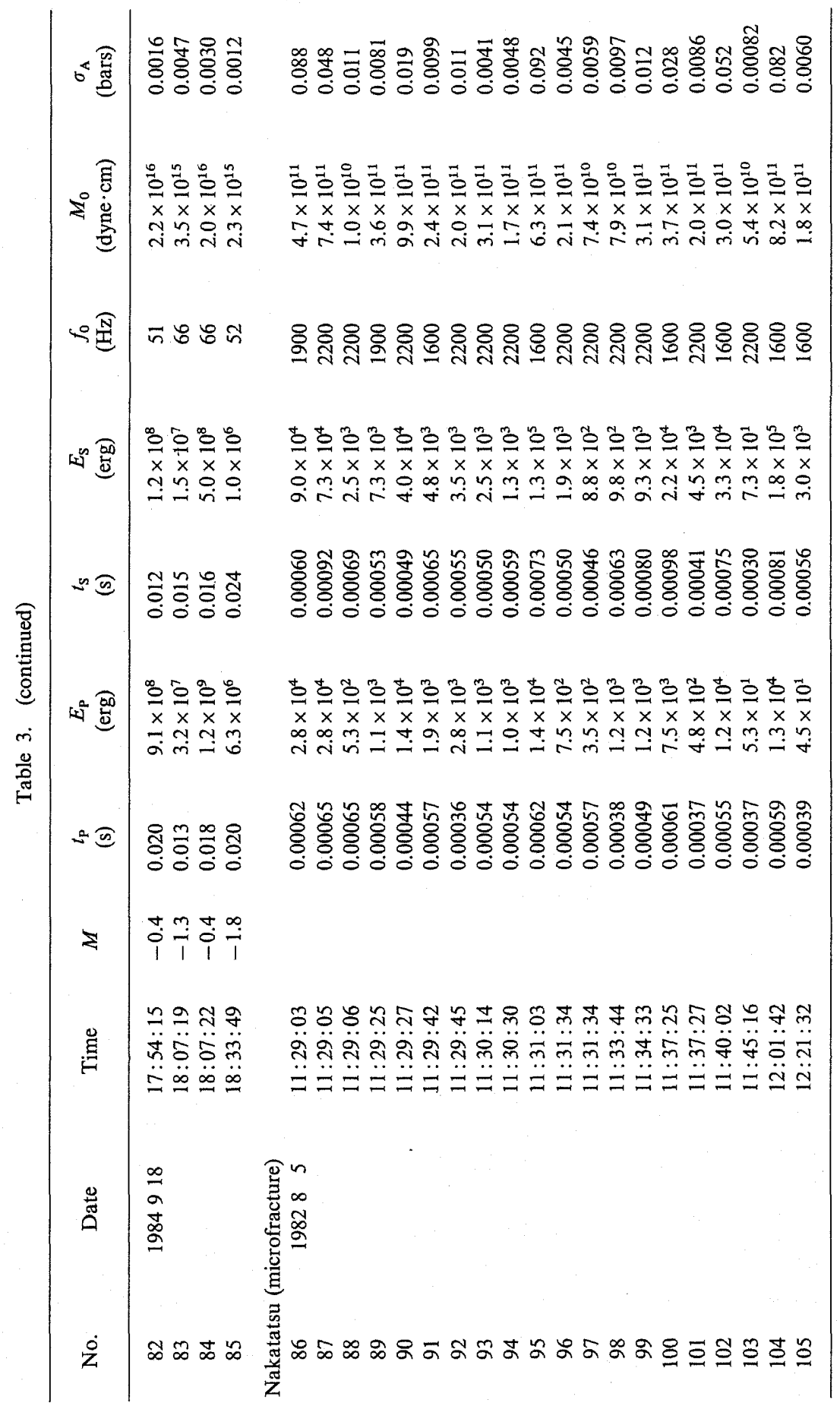




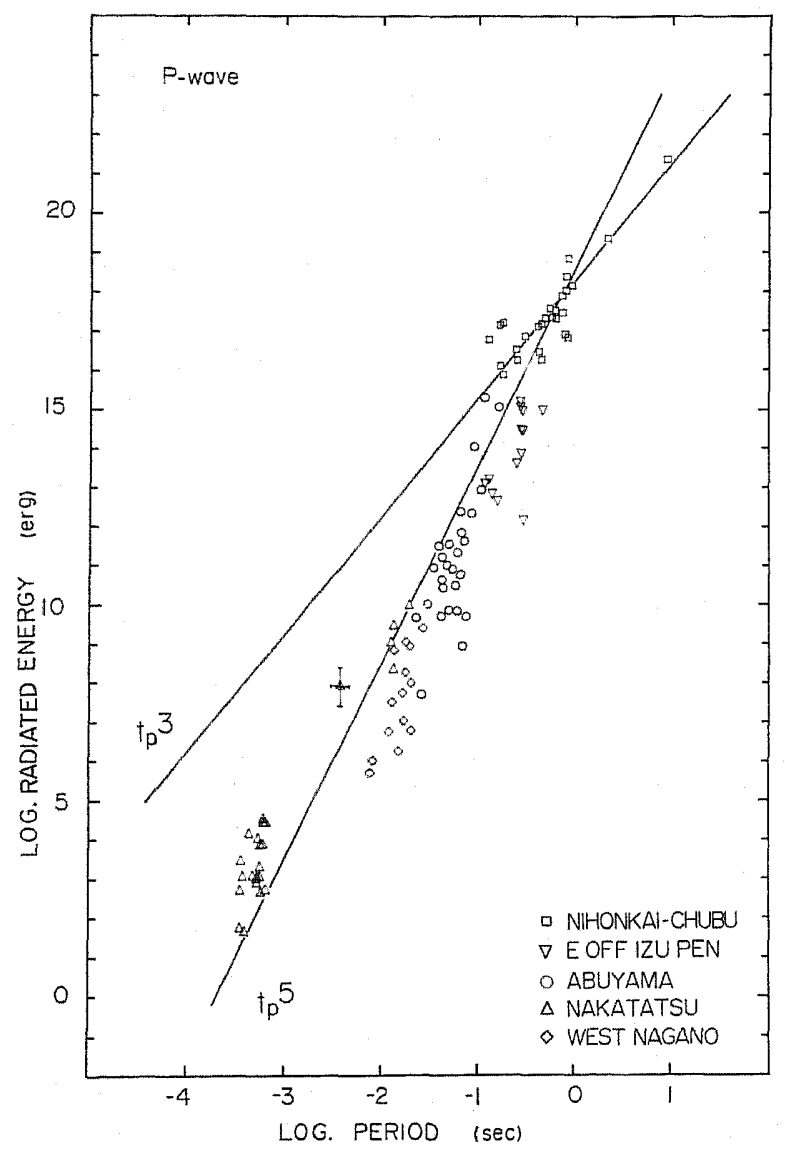

Fig. 5. Radiated energy of $\mathrm{P}$ wave $\left(E_{\mathrm{P}}\right)$ versus period of the first cycle of $\mathrm{P}$ wave velocity seismogram $\left(t_{\mathrm{p}}\right)$. The data plotted are not fitted by the straight line which represents the relation $E_{\mathrm{p}} \propto t_{\mathrm{p}}{ }^{3}$ but $E_{\mathrm{p}} \propto t_{\mathrm{p}}{ }^{5}$.

seismograms were clipping, $E_{\mathrm{P}}$ was obtained by extrapolating the recorded waveform (see Appendix 1).

The results are listed in Table 3 . The $E_{\mathrm{P}}-t_{\mathrm{p}}$ relation is shown in Fig. 5. Earthquake sequences are distinguished by symbols. The largest earthquake plotted is the largest Nihonkai-chubu aftershock and the second largest one is the second largest Nihonkai-chubu aftershock. $E_{\mathrm{p}}$ and $t_{\mathrm{p}}$ of the earthquakes plotted in this figure approximately range over twenty orders and five orders, respectively.

The straight line which represents the relation $E_{\mathrm{p}} \propto t_{\mathrm{p}}{ }^{5}$ fits almost all the data. If the cube law holds true, we will see that the relationship of $E_{\mathrm{p}}$ is proportional to $t_{\mathrm{p}}{ }^{3}$ (see Appendix 2). The straight line which represents the relation $E_{\mathrm{p}} \propto t_{\mathrm{P}}{ }^{3}$ is drawn to fit the data of the largest and second largest Nihonkai-chubu aftershock because the cube law holds for large earthquakes $\left(M_{0}>10^{25}\right.$ dyne $\left.\cdot \mathrm{cm}\right)$. However, the data of 
smaller earthquakes do not fitted to this line at all and deviate widely downward from it. We have concluded that the cube law does not hold for these data but that the relation $E_{\mathrm{P}} \propto t_{\mathrm{P}}{ }^{5}$ holds. Whereas, the datum of the largest Nihonkai-chubu aftershock deviates from the line which represents the relation $E_{\mathrm{p}} \propto t_{\mathrm{p}}{ }^{5}$. The relation $E_{\mathrm{P}} \propto t_{\mathrm{P}}^{5}$ does not likely hold true for large earthquakes $\left(M_{0}>10^{25} \mathrm{dyne} \cdot \mathrm{cm}\right)$.

\subsubsection{Relation between radiated energy and predominant period of $S$ wave}

The relationship between radiated energy and the predominant period of the $S$ wave was also investigated. The radiated energy of the $S$ wave was calculated in nearly the same way as with the $\mathrm{P}$ wave. We measured the double amplitude $A_{\mathrm{S}}$ and the period $t_{S}$ of the cycle which gave the maximum seismic energy of $S$ waves in one cycle in the three components of the velocity seismogram. For the earthquake sequence near Abuyama, the Nagano aftershocks and the microfractures in the Nakatatsu mine, $A_{\mathrm{S}}$ and $t_{\mathrm{s}}$ were measured in the vertical component, because only seismograms of the vertical component were obtained. $A_{\mathrm{S}}$ was corrected for the effect of anelastic attenuation. The corrected double amplitude $A_{\mathrm{S}}{ }^{*}$ was calculated by using the equation

$$
A_{\mathrm{S}}{ }^{*}=A_{\mathrm{S}} \exp \left(\pi R / Q_{\mathrm{s}} V_{\mathrm{S}} t_{\mathrm{S}}\right)
$$

where $V_{\mathrm{S}}$ is the average $\mathrm{S}$ wave velocity between source and receiver and $Q_{\mathrm{S}}$ is the $Q$ for the $\mathrm{S}$ wave. $V_{\mathrm{S}}$ was set to be $3.5 \mathrm{~km} / \mathrm{s}$. For the microfractures in the Nakatatsu mine, $V_{\mathrm{S}}$ was set to be $3.64 \mathrm{~km} / \mathrm{s}$. This value was obtained by dividing the $V_{\mathrm{P}}$ in the Nakatatsu mine $6.3 \mathrm{~km} / \mathrm{s}$ by $\sqrt{3} . Q_{\mathrm{S}}$ was taken to be 250 , or the half of the value of $Q_{\mathrm{P}}$ as mentioned by SAVAGE (1966) and WALSH (1966). The radiated energy of S wave $E_{\mathrm{S}}$ was calculated by the equation

$$
E_{\mathrm{S}}=(1 / 2) 4 \pi R^{2} \rho v_{\mathrm{S}} t_{\mathrm{S}}\left(A_{\mathrm{S}} * / 2 F R_{\theta \varphi}\right)^{2}
$$

where $v_{\mathrm{S}}$ is the near-site $\mathrm{S}$ wave velocity $(2.3 \mathrm{~km} / \mathrm{s})$. The $v_{\mathrm{S}}$ in the Nakatatsu mine is $3.64 \mathrm{~km} / \mathrm{s}$. The correction for the radiation pattern $R_{\theta \varphi}$ was assumed to be 0.6 following MALION and LONG (1980).

The $E_{\mathrm{S}}$ and $t_{\mathrm{S}}$ of the microfracture accompanied with aftershocks were estimated by analyzing the coda wave (see Appendix 1).

The $E_{\mathrm{S}}-t_{\mathrm{S}}$ relation is shown in Fig. 6. The largest earthquakes plotted is the second largest Nihonkai-chubu aftershock because the seismogram of the largest Nihonkai-chubu aftershock was clipped. The two straight lines were drawn in Fig. 6 . We find that the data are accurately represented by the line showing the relations $E_{\mathrm{S}} \propto t_{\mathrm{S}}{ }^{5}$, although the data vary widely. We have concluded that for both the P and S wave, radiated energy is proportional to the fifth power of the predominant period.

By the way, larger earthquakes of the East off Izu Peninsula swarm earthquakes group $(\nabla)$ have a fixed value of $t_{\mathrm{S}}$ (about $0.4 \mathrm{~s}$ ). This value seems to indicate the resonance frequency of the local foundation beneath the observation site. Since the $t_{\mathrm{S}}$ of smaller earthquakes was shorter than the value of $0.4 \mathrm{~s}$ and varied, this fixed value of $t_{\mathrm{S}}$ is not due to anelastic attenuation. $t_{\mathrm{S}}$ is not the period of the first cycle of $\mathrm{S}$ waves but the cycle which gives the maximum seismic energy of each $\mathrm{S}$ wave in one 


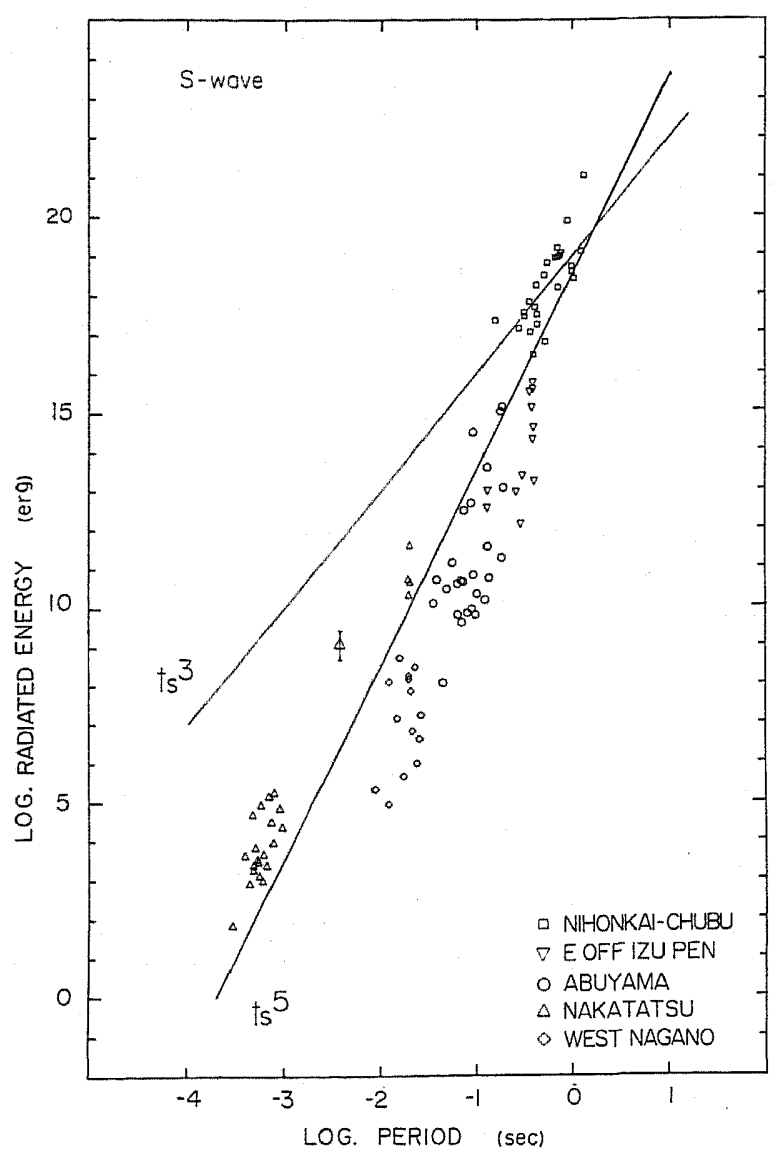

Fig. 6. Radiated energy of $S$ wave $\left(E_{S}\right)$ versus period of the cycle with the maximum seismic energy of $S$ wave velocity seismogram $\left(t_{\mathrm{S}}\right)$. The data plotted are not fitted by the straight line which represents the relation $E_{\mathrm{S}} \propto t_{\mathrm{S}}{ }^{3}$ but $E_{\mathrm{S}} \propto t_{\mathrm{S}}^{5}$.

cycle. We possibly measured the period of the cycle amplified by the local foundation. The resonance of the local foundation seems to occur if the frequency of an incident wave is nearly equal to the resonance frequency of the local foundation.

In this way, we should take a lot of care in analyzing $\mathrm{S}$ waves. In this paper, however, since radiated energies from the earthquakes used have a wide range, we are sure that the results were not seriously affected by the resonance of the local foundation.

\subsubsection{Effect of anelastic attenuation}

In the above investigation of the relationship between radiated energy and the predominant period, $Q_{\mathrm{P}}$ and $Q_{\mathrm{S}}$ were taken to be 500 and 250, respectively, for the 
$7 / 313: 1 \oslash M=-0.3$
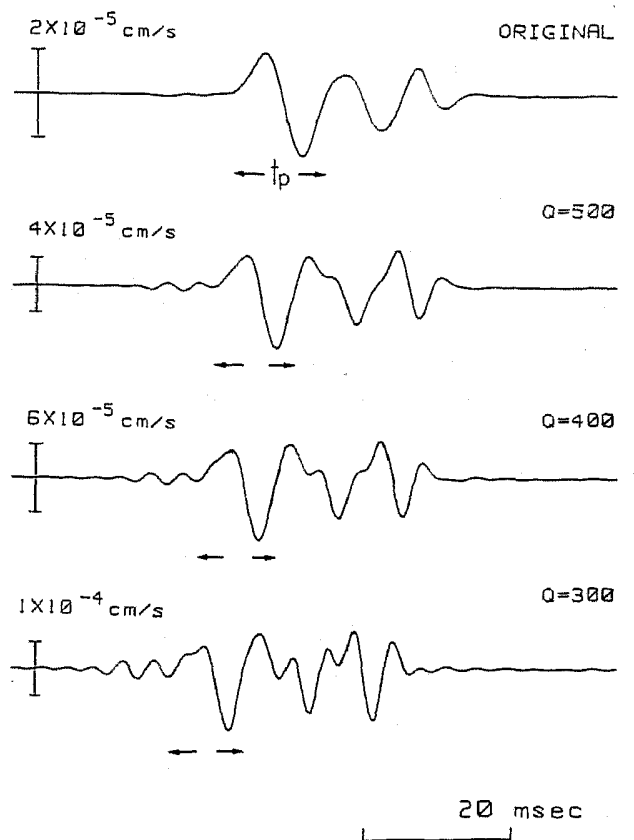

Fig. 7. Change of the deconvolved $P$ waveform against the different values of $Q_{\mathrm{P}}$, which are 500,400 , and 300 . The seismogram was observed in the Nakatatsu mine. Only initial parts of $\mathrm{P}$ waves are shown. $t_{\mathrm{P}}$ is almost constant and independent of $Q_{\mathrm{p}}$.

correction of anelastic attenuation. These values of $Q_{\mathrm{P}}$ and $Q_{\mathrm{S}}$ are equal to those used in the studies mentioned above which investigated the relationship between $M_{0}$ and the source radius $(r)$ by using body wave spectra (e.g., THATCHER and HANKs, 1973; MALION and LoNG, 1980). In this section, we will show that even if $Q_{P}$ is set to 300 , it is not necessary to change the results in the previous sections.

We are sure that the most appropriate procedure of the correction for the effect of anelastic attenuation is the deconvolution of its effect. Here, by using Azimi's attenuation law (AzIMI et al., 1968), we will investigate the change of the $\mathrm{P}$ waveform against the different values of $Q_{\mathrm{p}}$, which are 500,400 , and 300 . Figure 7 demonstrates the change in the initial part of the velocity waveform with an earthquake observed at the Nakatatsu mine. The $t_{\mathrm{P}}$ of this earthquake is $0.012 \mathrm{~s}$. This earthquake needs the largest correction for the effect of anelastic attenuation by using Eq. (1) (a factor of about 2.5) of all earthquakes analyzed in this paper. We find that the period of the first cycle corrected by $Q_{\mathrm{P}}=300$ is about $30 \%$ shorter than that corrected by $Q_{\mathrm{P}}=500$ and that the double amplitude of the first cycle corrected by $Q_{\mathrm{P}}=300$ is only about five times as large as that corrected by $Q_{\mathrm{P}}=500$. These 


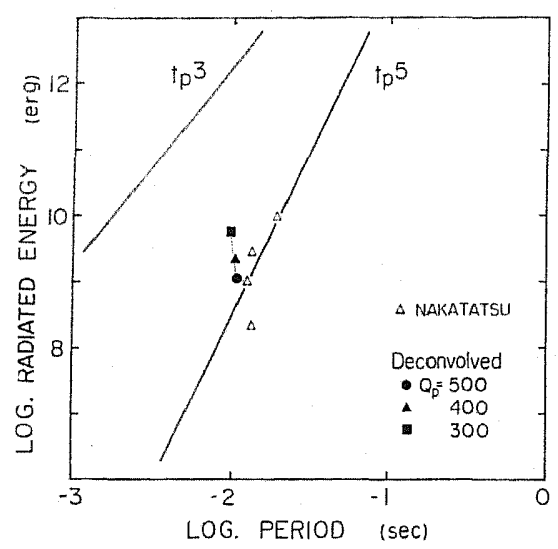

Fig. 8. Representation of the change of the deconvolved waveform on $E_{\mathrm{P}}-t_{\mathrm{P}}$ plots. The data were obtained from the deconvolved waveforms shown in Fig. 7. The two straight lines in this figure are the same as in Fig. 5. The deconvolved datum deviates widely downward from the straight line $\left(E_{\mathrm{P}} \propto t_{\mathrm{P}}{ }^{3}\right)$, even if $Q_{\mathrm{P}}=300$.

results are illustrated in Fig. 8 by $E_{\mathrm{P}}-t_{\mathrm{P}}$ representation. The two straight lines in this figure represents the same relation as in Fig. 5. We find that even if $Q_{\mathrm{P}}$ is assumed to be 300 , the corrected datum deviates widely downward from the straight line which represents the relation $E_{\mathrm{p}} \propto t_{\mathrm{p}}{ }^{3}$ but it is fitted well by the straight line which represents the relation $E_{\mathrm{p}} \propto t_{\mathrm{P}}{ }^{5}$. The changes in $\mathrm{P}$ waveforms of other earthquakes are much smaller than that shown in Fig. 8 because the correction using Eq. (1) for other earthquakes is much smaller than that for the earthquake shown in Fig. 8. Therefore, we conclude that the relation $E_{\mathrm{P}} \propto t_{\mathrm{P}}{ }^{5}$ need not be changed even if $Q_{\mathrm{P}}$ is set to 300 . This clearly shows that the earthquakes observed at relatively short focal distances are scarcely affected by the effect of anelastic attenuation.

In the above sections, $t_{\mathrm{P}}$ and $t_{\mathrm{S}}$ were not corrected for the effect of anelastic attenuation, while $A_{\mathrm{P}}$ and $A_{\mathrm{S}}$ were corrected by using Eqs. (1) and (4), respectively. Since the period of the first cycle scarcely changes in the deconvolution of the effect of anelastic attenuation as shown in Figs. 7 and $8, t_{\mathrm{P}}$ has no need for correcting it. The same thing is mentioned for $t_{\mathrm{s}}$.

\subsection{Relation between seismic moment and corner frequency}

\subsection{Relation between seismic moment and corner frequency of $P$ wave}

We will investigate the relation between seismic moment and corner frequency to verify the results in the previous sections. The method of the data analysis is almost the same as other studies that have investigated body wave spectra (e.g., HANKS and Wyss, 1972; THATCHER and HANKS, 1973). P wave velocity seismograms in the vertical component were used in this analysis. The Fourier transform of the waveform of the first five cycles was computed by using a Fast Fourier transform 
algorithm. The reason the waveform of the first five cycles was analyzed is that the analysis of only the first cycle cannot give a good resolution of corner frequency. However, since the $\mathrm{P}$ wave velocity seismograms used in this analysis are dominated in amplitude by the first cycle, the error in spectral amplitude resulting from the sample length of the first five cycles is negligible. The waveforms between the onsets of $\mathrm{P}$ and $\mathrm{S}$ waves were analyzed for the largest and second largest Nihonkai-chubu aftershocks and the microfractures induced by an explosion because their S-P times are not five times as long as their periods.

The spectrum was corrected for the effects of instrumental response and anelastic attenuation. The effect of anelastic attenuation was removed by using the usual exponential attenuation law with a $Q_{\mathrm{P}}$ of 500. For the microfractures induced by an explosion, this effect was disregarded as mentioned in the above section. Examples of the resulting displacement spectra of $\mathbf{P}$ waves normalized to the focal distance of $1 \mathrm{~km}$ are shown in Figs. 9(a)-9(d).

The spectrum was approximated with a constant long-period level $\Omega_{0}$, corner frequency $f_{0}$ and a high frequency asymptote $f^{-n}$. However, the $f_{0}$ of the largest Nihonkai-chubu aftershock was not determined because its S-P time is as long as its $t_{\mathrm{p}}$. The determined corner frequency $f_{0}$ is in strong agreement with the $1 / t_{\mathrm{P}}$ obtained in section 3.1.1. In the case of the microfracture accompanied with aftershocks, $\Omega_{0}$ was determined from the analytical Fourier transform of the estimated waveform (see Appendix 1) and $f_{0}$ was calculated by $1 / t_{\mathrm{p}}$.

Finally, the seismic moment $M_{0}$ was calculated by the formula (KEILIS-BoroK, 1960),

$$
M_{0}=4 \pi R^{3} V_{\mathrm{p}}^{3} \Omega_{0} / F R_{\theta \varphi} .
$$

The relationship between $M_{0}$ and $f_{0}$ is shown in Fig. 10. The largest earthquake plotted is the second largest Nihonkai-chubu aftershock. We find the straight line that represents the relation $M_{0} \propto f_{0}^{-2}$ fits almost all the data. The straight line which represents the relation $M_{0} \propto f_{0}^{-3}$ is also drawn to fit the datum of the second largest Nihonkai-chubu aftershock. However, the data of smaller earthquakes are not adequately measured by this line at all. We have concluded that the cube law does not hold true for earthquakes of which $10^{10}<M_{0}<10^{25}$ dyne $\cdot \mathrm{cm}$.

\subsubsection{Effect of depth}

We will investigate the effect of depth on a waveform and estimate the correction for this effect. In the investigation of the scaling relations, it is desirable that every earthquake analyzed occur at an almost equal depth. However, as shown in Table 1, the depths of the earthquakes analyzed in this paper distribute from about 0.7 to $20 \mathrm{~km}$.

The effects of depth have been studied in several papers. WYSS and BRUNE (1971) found an increase in apparent stress $\left(\sigma_{\mathrm{A}}\right)$ with depth for small earthquakes in the Borrego Mountain region. Mikumo (1971) indicated an increase in stress drop with depth for deep and intermediate earthquakes. HARTZELL and BRUNE (1977) showed an increase in stress drop with depth for crustal earthquakes. In this way, 
Y. I10
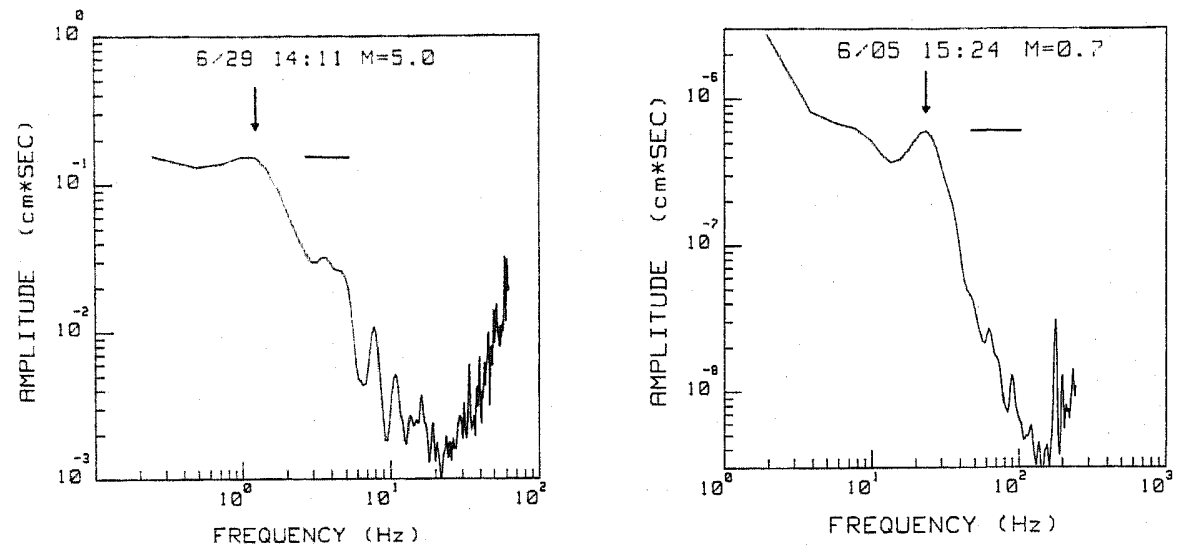

$8 \times 10^{-2} \mathrm{~cm} / \mathrm{s}$

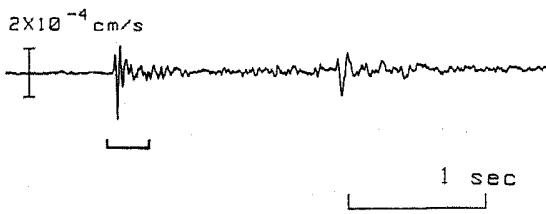

(b)
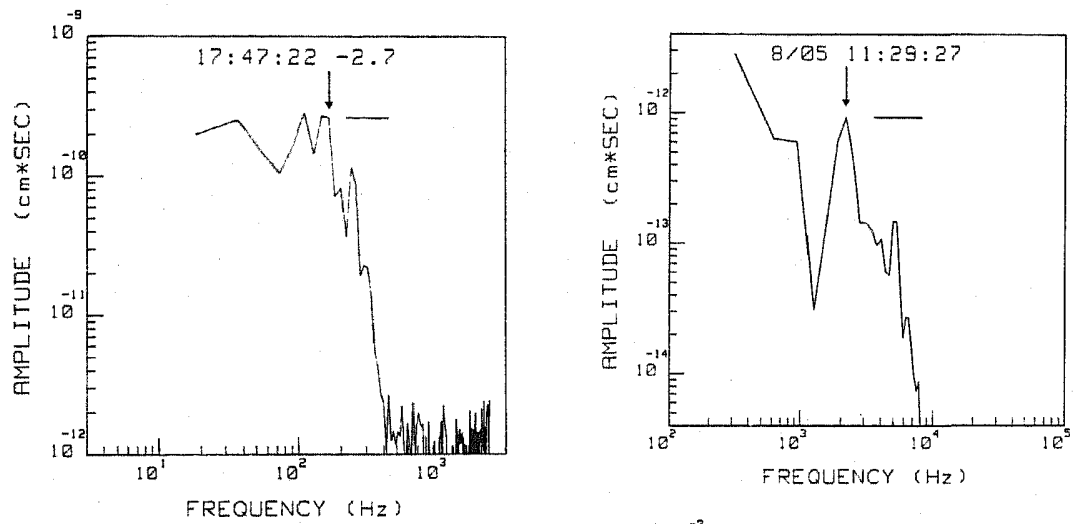

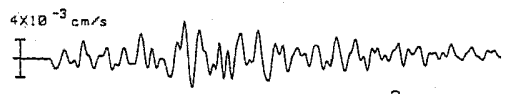

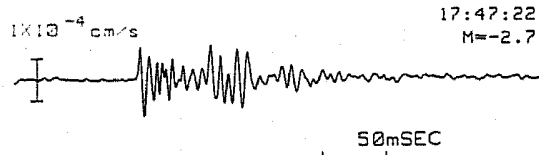

(c)

(d)

Fig. 9 


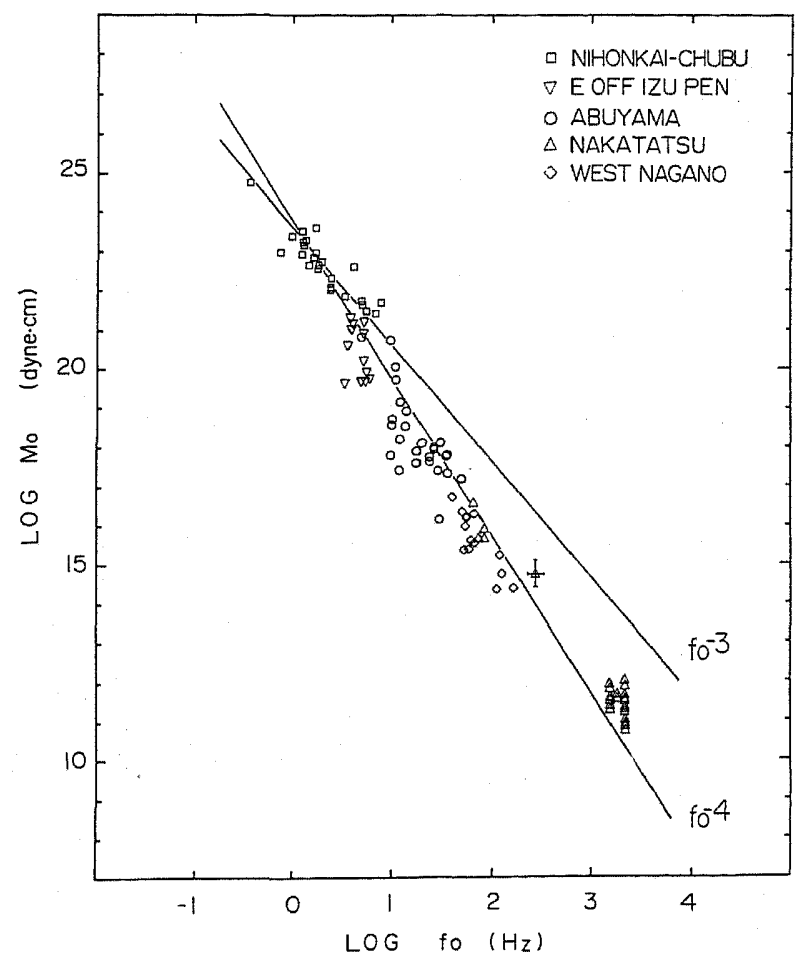

Fig. 10. Seismic moment $\left(M_{0}\right)$ versus corner frequency of $\mathbf{P}$ wave $\left(f_{0}\right)$. The data plotted aren't fitted by the straight line which represents the cube law $M_{0} \propto f_{0}^{-3}$ but $M_{0} \propto f_{0}^{-4}$.

depth seems to affect stress drop.

Here, following Mाкumo (1971), we represent stress drop by the equation

$$
\Delta \sigma=\Delta \sigma_{0}+\Delta \mu(1-\lambda) \sigma_{\mathrm{n}}
$$

where $\sigma_{\mathrm{n}}$ is normal stress, $\Delta \sigma_{0}$ is the difference between the initial and final frictional stresses of zero normal stress, $\Delta \mu$ is the difference between the initial and final coefficient of friction across the fault plane and $\lambda$ is the pore pressure divided by $\sigma_{\mathrm{n}}$.

Fig. 9. (a) Seismogram and $\mathrm{P}$ wave displacement spectrum of the aftershock of the 1984 Nihonkai-chubu earthquake. The spectrum was normalized to a focal distance of $1 \mathrm{~km}$. An arrow and horizontal line indicate corner frequency of $P$ waves $\left(f_{0}\right)$ and long period flat level $\Omega_{0}$, respectively. A bracket under the trace indicates the portion analyzed. (b) Seismogram and $\mathrm{P}$ wave displacement spectrum of the earthquake near Abuyama. (c) Seismogram and P wave displacement spectrum of the aftershock of the 1984 Western Nagano Prefecture earthquake. (d) Seismogram and $\mathbf{P}$ wave displacement spectrum of the microfracture induced by an explosion in the Nakatatsu mine. 
We are sure that normal stress increases with depth. However, the other parameters are unknown. So the following is assumed: 1) $\Delta \sigma_{0}=0$; 2) $\sigma_{\mathrm{n}}=k_{1} h$ where $h$ is the depth and $k_{1}$ is the constant; 3$) \Delta \mu$ and $\lambda$ are constant independent of depth. Then, (7) becomes

$$
\Delta \sigma=k_{2} h
$$

where $k_{2}$ is the constant of $\Delta \mu(1-\lambda) k_{1}$. This Eq. (8) shows that stress drop is proportional to depth and enables us to correct stress drop for the effect of depth. Then, we normalize the referent depth of hypocenters to $10 \mathrm{~km}$. The corrected stress drop $\Delta \sigma_{10}$ is calculated by the equation

$$
\Delta \sigma_{10}=(10 / h) \Delta \sigma .
$$

However, the stress drop calculated by Eq. ( 8 ) is too small when the hypocenter is located near the ground surface, because $\sigma_{\mathrm{n}}$ is not zero during the faulting even if $h=0 \mathrm{~km}$. Consequently, Eq. (9) likely gives the upper limit of the correction.

We will calculate the correction of stress drop for the Nagano aftershocks by using (9). Though the hypocenters of the Nagano aftershocks analyzed in this paper could not be determined, we regard the focal distances as the focal depths, because their waveforms imply that the hypocenters are located right beneath the observation site.

We demonstrate this correction of stress drop on $M_{0}-f_{0}$ plots. Stress drop is represented from BRUNE (1970) as follows,

$$
\Delta \sigma=(7 / 16)\left(M_{0} / r^{3}\right) \text {. }
$$

Here, we assume average rupture velocity does not change with depth. Then, the fault radius $r$ is inversely proportional to $f_{0}$ and the proportional coefficient does not change with depth (see Appendix 3). With $f_{0}$ replacing $r$, Eq. (10) becomes

$$
\Delta \sigma=k_{3} M_{0} f_{0}^{3}
$$

where $k_{3}$ is the constant. The correction of stress drop is attributed to that of $M_{0}$ and $f_{0}$. As shown in the later section, average rupture velocity depends on earthquake size. However, we disregarded the change of average rupture velocity against the small correction of $M_{0}$ because its dependence was very weak in the manner $V_{\mathrm{r}} \propto M_{0}^{0.18} \sim M_{0}^{0.38}$.

Figure 11 illustrates the correction of $M_{0}$ or $f_{0}$ for the Nagano aftershocks. Figure 11 a shows the correction of $M_{0}$ against the constant $f_{0}$ and Fig. $11 \mathrm{~b}$ the correction of $f_{0}$ against the constant $M_{0}$. The two straight lines in this figure represent the same relation as that in Fig. 10. The corrected data still deviate widely downward from the straight line, which represents the relation $M_{0} \propto f_{0}^{-3}$. We found that the corrections achieved here are small. Furthermore, the correction achieved by Eq. (9) gives the upper limit as mentioned above. Therefore, we disregard the effect of depth for the Nagano aftershocks.

For the microfracture accompanied with aftershocks in the Nakatatsu mine, 

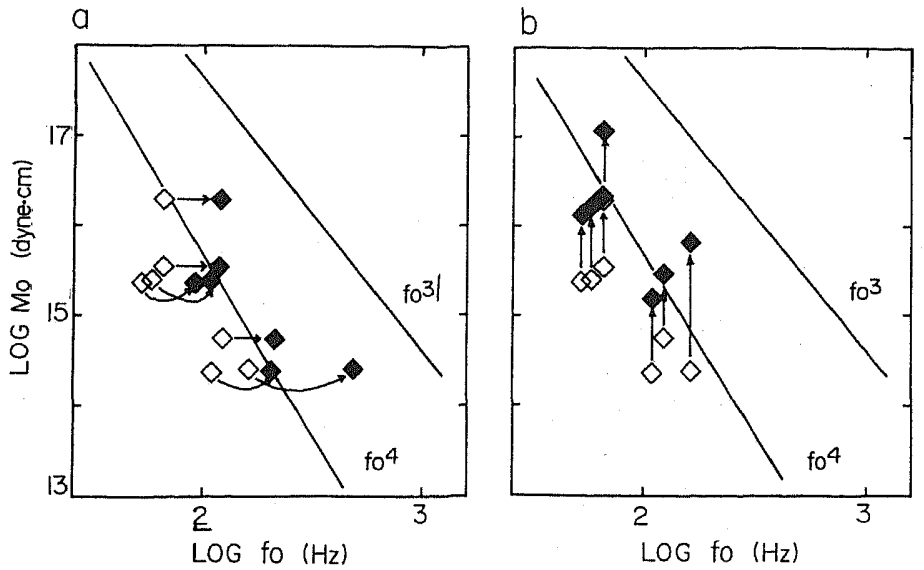

Fig. 11. Corrections for the effect of depth for the aftershocks of the 1984 Western Nagano Prefecture earthquake are demonstrated by $M_{0}-f_{0}$ plots. Open and closed diamonds indicate the original and corrected data, respectively. (a) Correction of $f_{0}$ against constant seismic moment. (b) Correction of $M_{0}$ against constant corner frequency. The two straight lines in this figure are the same as in Fig. 10.

the stress drop was determined without assuming the rupture velocity, because its aftershock distribution was determined by IIo (1984b). The stress drop was calculated to be between 250 to 2,000 bars, as shown in Appendix 1. This value of stress drop is larger than that of large earthquakes $\left(M_{0}>10^{25}\right.$ dyne $\left.\cdot \mathrm{cm}\right)$ or about 10 to 100 bars (KANAMORI and ANDERSON, 1975). The microfracture accompanied with aftershocks was induced by the stress concentration resulting from the excavation of tunnels (Iro, 1984 b). Consequently, this large value of the stress drop is likely because the normal stress across the fault plane was almost as large as that at a depth of $10 \mathrm{~km}$ because of the stress concentration. The microfractures induced by an explosion were also caused by the stress concentration on a small region (Iro, 1984 a). Therefore, we have concluded that the correction for the effect of depth is not necessary for the microfractures in the Nakatatsu mine.

For other earthquake sequences, since almost all the depth of hypocenters are concentrated from 5 to $15 \mathrm{~km}$, we have concluded that the correction for the effect of depth is small enough so as to be negligible. For example, Fig. 12 shows the $M_{0}-f_{0}$ plots for the earthquakes near Abuyama which are divided into three depth ranges. The hypocentral data were obtained by the routine processing of the telemetered array system for microearthquake observation at Abuyama Seismological Observatory (KuroIso and WaTANABE, 1977). The difference in the $M_{0}-f_{0}$ plots between these three data sets cannot be detected from Fig. 12. The correction for the effect of depth is not given for the earthquakes near Abuyama, the aftershocks of the 1984 Nihonkai-chubu earthquake and the East off Izu Peninsula swarm earthquakes. 


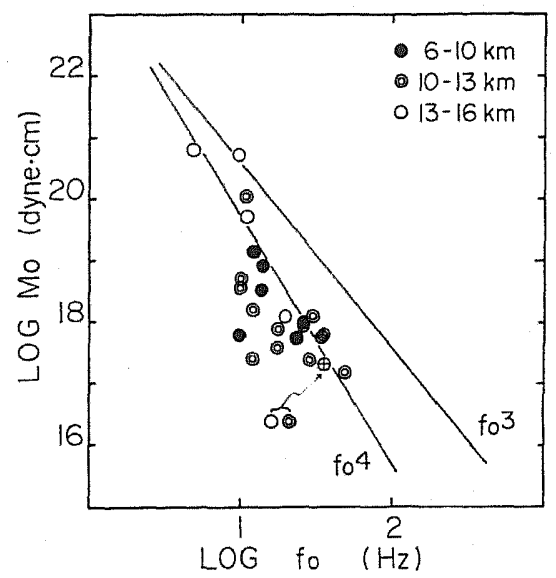

Fig. 12. Representation of $M_{0}-f_{0}$ for the earthquakes near Abuyama. The data are divided into three depth ranges. The two data overlap each other at the point of the circle with the cross. The two straight lines in this figure are the same as in Fig. 10.

Velocity

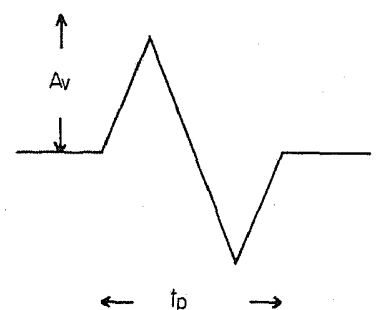

$\leftarrow$ tp $\rightarrow$
Displacement

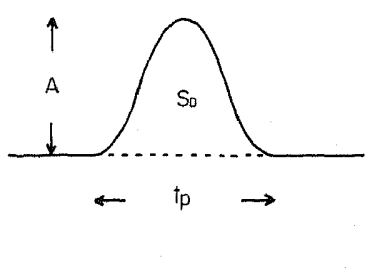

Fig. 13. Schematic velocity and displacement $P$ pulse shapes illustrating the measurements of amplitude and period.

From the above investigation, we have concluded that the correction for the effect of depth is small enough to disregard for all the earthquakes analyzed in this paper.

\subsection{Scaling of pulse shape}

Analyzing the waveforms of earthquakes of which $10^{10}<M_{0}<10^{25} \mathrm{dyne} \cdot \mathrm{cm}$, we found the following: 1) radiated energy is proportional to the fifth power of the predominant period; 2) the seismic moment is inversely proportional to the fourth power of corner frequency. In this section, we will show that these two results are consistent with each other and that the scaling law of far field $\mathrm{P}$ pulse shape is derived from these results.

The schematic velocity and displacement pulse shapes of a far field $P$ wave are shown in Fig. 13. We find from Fig. 1 that the first cycle of $\mathrm{P}$ wave velocity 
seismograms used in this study is modeled as Fig. 13. The displacement pulse was obtained by the integral calculus of the velocity pulse.

Now, at one and the same focal distance, the relation $E_{\mathrm{p}} \propto A_{\mathrm{v}}{ }^{2} \cdot t_{\mathrm{p}}$ holds true from Eq. (2). Combining this with the relation $E_{\mathrm{P}} \propto t_{\mathrm{P}}{ }^{5}$, we obtain

$$
A_{\mathrm{v}} \propto t_{\mathrm{P}}^{2} \text {. }
$$

Here, we find from the scaling law of the velocity pulse of the far field $\mathrm{P}$ wave that the amplitude of velocity pulse is proportional to the square of its period. Since the displacement pulse is obtained by the integral calculus of the velocity pulse, the amplitude of the displacement pulse $(A)$ is represented as $A=(1 / 4) A_{\mathrm{v}} t_{\mathrm{p}}$. From (12), the relation

$$
A \propto t_{\mathrm{P}}{ }^{3}
$$

is obtained. We find from the scaling law of the displacement pulse of far field $\mathrm{P}$ wave that the amplitude of displacement $\mathrm{P}$ pulse is proportional to the cube of its pulse width.

From Eq. (6), the seismic moment is proportional to the area under the displacement pulse $\left(S_{\mathrm{D}}\right)$ and $S_{\mathrm{D}}$, and is represented as $S_{\mathrm{D}}=(1 / 2) A t_{\mathrm{p}}$. Using Eq. (13), we obtain

$$
M_{0} \propto t_{\mathrm{P}}^{4} .
$$

With $f_{0}$ replacing $t_{\mathrm{p}}$ by using the equation $f_{0}=1 / t_{\mathrm{p}}$, Eq. (14) becomes $M_{0} \propto f_{0}{ }^{-4}$. In this way, the relation $M_{0} \propto f_{0}^{-4}$ is derived from the relation $E_{\mathrm{P}} \propto t_{\mathrm{P}}{ }^{5}$. This indicates that the two relations are consistent with each other.

\section{Fault Parameters}

\subsection{Relation between seismic moment and fault length}

We concluded in the previous sections that the cube law $\left(M_{0} \propto f_{0}^{-3}\right)$ which is generally accepted for large earthquakes $\left(M_{0}>10^{25}\right.$ dyne $\left.\cdot \mathrm{cm}\right)$ does not hold true for earthquakes of which $10^{10}<M_{0}<10^{25} \mathrm{dyne} \cdot \mathrm{cm}$. We found that the corner frequencies of microearthquakes are lower than those derived from the cube law. This result agrees with the studies that achieved a waveform analysis for microearthquakes (e.g., Chouet et al., 1978; Malion and LonG, 1980). However, these studies have assumed that the constant rupture velocity was almost equal to that of large earthquakes and have attributed lower corner frequencies to smaller stress drops.

We will investigate the relation between $M_{0}$ and fault length $L$ and settle whether stress drops of microearthquakes and small earthquakes are smaller than those of large earthquakes or not. Here, we assume the relation $W \propto L$. If rupture velocity is assumed to be constant independent of earthquake size, the relation $f_{0} \propto 1 / L$ remains true (see Appendix 3). By combining this with the relation $M_{0} \propto f_{0}^{-4}$, we obtain the relation $M_{0} \propto L^{4}$. In this case, stress drop is proportional to $L$ and decreases with the decreasing seismic moment. On the other hand, if the 
Table 4. Fault length of small to moderate earthquakes.

\begin{tabular}{|c|c|c|c|c|}
\hline No. & Date & Region & $M$ & $L(\mathrm{~km})$ \\
\hline 1 & Feb. $\quad 9,1977$ & near Abuyama & 3.9 & $0.83^{1)}$ \\
\hline 2 & Nov. 25,1977 & near Abuyama & 3.8 & $0.93^{1)}$ \\
\hline 3 & Jan. $\quad 7,1978$ & near Abuyama & 4.0 & $0.81^{1)}$ \\
\hline 4 & Sep. 11,1980 & Lake Biwa & 4.6 & $1.70^{2)}$ \\
\hline 5 & Feb. 3,1981 & Myokensan & 3.8 & $0.70^{3)}$ \\
\hline 6 & Mar. 16,1983 & near Lake Hamana & 5.7 & $4.5^{4)}$ \\
\hline 7 & Aug. $\quad 8,1983$ & $\begin{array}{l}\text { Eastern Part of } \\
\text { Yamanashi Prefecture }\end{array}$ & 6.0 & $8.7^{51}$ \\
\hline 8 & Oct. 31,1983 & $\begin{array}{l}\text { Central Part of } \\
\text { Tottori Prefecture }\end{array}$ & 6.2 & $7.1^{6)}$ \\
\hline 9 & Nov. 16,1983 & near Kyoto City & 3.8 & $1.0^{7)}$ \\
\hline 10 & Nov. 24,1983 & near Lake Hamanako & 5.0 & $3.6^{8)}$ \\
\hline 11 & May 5,1984 & $\begin{array}{l}\text { Oyamazaki-cho in } \\
\text { Kyoto Prefecture }\end{array}$ & 4.6 & $1.6^{9)}$ \\
\hline 12 & Jun. 30,1984 & Yamasaki Fault & 5.5 & $4.7^{10)}$ \\
\hline
\end{tabular}

References to Table 4. 1) ITo and Kuroiso (1979), ${ }^{2)}$ MAEDA and Kuroiso (1981), "3) Iro and Kuroiso (1981), ${ }^{4}$ National Research Center for Disaster Prevention (1983), ${ }^{5}$ National Research Center for Disaster Prevention (1984a), ${ }^{6}$ TotTori Microearthquake Observatory and Microearthquake Research Section, Disaster Prevention Research INSTITUTE, KYOTO UNIVERSITY and INSTITUTE OF EARTHSCIENCES, TOTTORI UNIVERSITY (1984), 7) Faculty of Science, Kyoto University and Disaster Prevention Research Institute (1984), ${ }^{8)}$ National Research Center for Disaster Prevention (1984b), ${ }^{9}$ Kuroiso et al. $(1984),{ }^{10)}$ The Research Group for the Yamasaki Fault (1985).

similarity law remains true between the static fault parameters of the fault length $L$, the fault width $W$ and the average dislocation $D$, the relation $M_{0} \propto L^{3}$ must remain true and the stress drop must have a constant value independent of earthquake size.

We are sure that the most suitable method to determine $L$ is to use aftershock distributions. In recent years, the telemetered array systems for microearthquake observation has begun to be used and hypocentral determination has come to be extremely precise. Since the error in relative hypocentral determination is about $100 \mathrm{~m}$ at most, the precise hypocentral distribution of aftershocks of small earthquakes with a magnitude of about 4 was able to be determined (ITo and Kuroiso, 1979).

First, we will investigate the relationship between the magnitude determined by J.M.A. $(M)$ and $L$ by using the aftershock distributions of small to moderate earthquakes. The earthquakes used here are listed in Table 4. These earthquakes occurred within the networks of microearthquake observation and their aftershock distributions were published. Their magnitudes are limited to about 6 because the relation $M_{0} \propto f_{0}^{-4}$ holds for earthquakes with a magnitude smaller than about 6 .

The epicentral distributions of these earthquakes was surrounded by an ellipse. The major axis of this ellipse was regarded as the fault length. For example, the aftershock distribution of the earthquake occurring at Oyamazaki-cho in Kyoto 


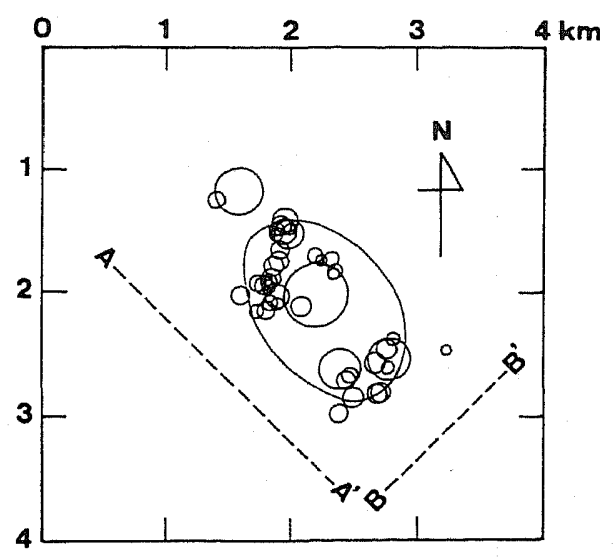

Fig. 14. Example of aftershock distribution: the earthquake at Oyamazaki-cho in Kyoto Prefecture. $M=4.6$ (after KuRorso et al., 1984). The major axis of the ellipse is regarded as the fault length of the main shock.

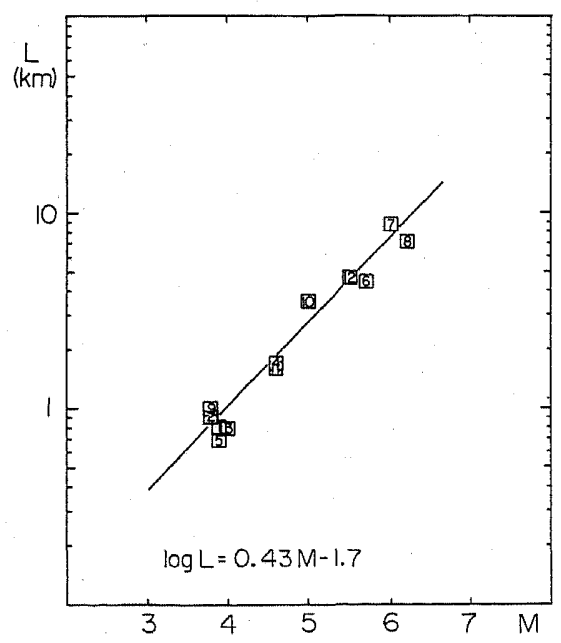

Fig. 15. Fault length versus magnitude for small to moderate earthquakes. The numbers correspond to those in Table 4.

Prefecture on May 5, 1984 is shown in Fig. 14. The relation between $M$ and $L$ is shown in Fig. 15. The relation

$$
\log L=0.43 M-1.7
$$

was computed using a least square program, where $L$ is the fault length $(\mathrm{km})$ and $M$ is the magnitude by J.M.A.

Furthermore, as mentioned in Appendix 1, the fault length of the microfracture accompanied with aftershocks was estimated to be 1 to $2 \mathrm{~m}$. For the microfractures 


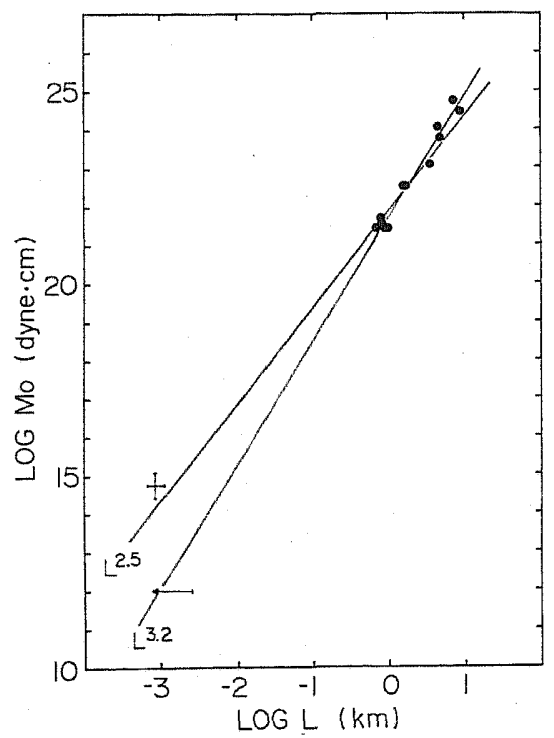

Fig. 16. Seismic moment versus fault length. The datum with error bars is the microfracture accompanied with aftershocks. The arrow with a bar indicates the upper limit of the fault length of the microfracture induced by an explosion with the maximum seismic moment calculated in section 3.2.1.

Table 5. Source data of the microfracture accompanied with aftershocks.

\begin{tabular}{ccccccc}
\hline CH. No. & $\begin{array}{c}t_{\mathrm{p}} \\
(\mathrm{ms})\end{array}$ & $\begin{array}{c}E_{\mathrm{P}} \\
(\mathrm{erg})\end{array}$ & $\begin{array}{c}t_{\mathrm{S}} \\
(\mathrm{ms})\end{array}$ & $\begin{array}{c}E_{\mathrm{S}} \\
(\mathrm{erg})\end{array}$ & $\begin{array}{c}M_{0} \\
(\mathrm{dyne} \cdot \mathrm{cm})\end{array}$ & $\begin{array}{c}\sigma_{\mathrm{A}} \\
(\text { bars })\end{array}$ \\
\hline 1 & 3.8 & $2.5 \times 10^{8}$ & 3.8 & $1.0 \times 10^{9}$ & $1.2 \times 10^{15}$ & 0.37 \\
2 & 3.6 & $1.4 \times 10^{8}$ & 3.8 & $4.7 \times 10^{8}$ & $8.3 \times 10^{14}$ & 0.26 \\
3 & 3.7 & $1.1 \times 10^{8}$ & 3.8 & $1.7 \times 10^{9}$ & $7.6 \times 10^{14}$ & 0.84 \\
4 & 4.7 & $6.9 \times 10^{7}$ & 3.8 & $6.7 \times 10^{8}$ & $8.5 \times 10^{14}$ & 0.30 \\
5 & 3.0 & $2.4 \times 10^{7}$ & 3.8 & $1.3 \times 10^{9}$ & $2.7 \times 10^{14}$ & 1.7 \\
9 & 4.4 & $1.3 \times 10^{8}$ & 3.8 & $1.0 \times 10^{9}$ & $1.1 \times 10^{15}$ & 0.38 \\
\hline
\end{tabular}

induced by an explosion, the upper limit of the fault length is given by their hypocentral distribution.

The relation between $M_{0}$ and $L$ is shown in Fig. 16. Since the seismic moments of almost all the earthquakes listed in Table 4 had not been determined, $M_{0}$ was calculated from $M$ by using the equation

$$
\log M_{0}=1.37 M+16.2
$$

which is described in Appendix 4. The datum with error bars is the microfracture accompanied with aftershocks. The arrow shows the upper limit of the fault length $(2.5 \mathrm{~m})$ for the microfracture induced by an explosion of the maximum seismic 
moment calculated above. The straight line which represents the equation

$$
\log M_{0}=3.2 \log L+21.6
$$

is drawn in Fig. 16. This equation was derived from Eqs. (15) and (16). The datum of the microfracture accompanied with aftershocks deviates slightly from this line. The other straight line is drawn visually to fit the data of both the microfractures and the small to moderate earthquakes. This line represents the relation $M_{0} \propto L^{2.5}$.

As shown in Fig. 16, the scaling relation between $M_{0}$ and $L$ is not complete because of the lack of data for earthquakes of which $M<3$. However, we have concluded that at least the value of the coefficient $k$ in the relation $M_{0} \propto L^{k}$ is approximately between 2.5 to 3.2 . Even if $k$ takes the maximum value, it is much smaller than the value of 4 which is derived from the assumption of a constant rupture velocity. Consequently, the relation $M_{0} \propto f_{0}{ }^{-4}$ cannot be explained by the assumption that rupture velocity is constant, independent of earthquake size. This shows rupture velocity changes with earthquake size. On the contrary, the value of $k$ indicates $\Delta \sigma$ is almost constant and is independent of earthquake size.

\subsection{Dependence of rupture velocity on earthquake size}

In this section, we will investigate the relationship between rupture velocity and fault length. As shown in section 3.1.1, SATO and HIRASAwa (1973) indicated the rupture velocity $V_{\mathrm{r}}$ is related to the fault length $L$ in the manner of the equation

$$
t_{\mathrm{P}}=L / 2 V_{\mathrm{r}}
$$

for the circular fault. By using Eq. (18), eliminating $t_{\mathrm{p}}$ in Eq. (14), the relation Eq. (14) becomes $M_{0} \propto\left(L / V_{\mathrm{r}}\right)^{4}$. By using the relation $M_{0} \propto L^{2.5} \sim L^{3.2}$ obtained in the previous section, replacing $M_{0}$ with $L$, the relation between $V_{\mathrm{r}}$ and $L$ is obtained as follows

$$
V_{\mathrm{r}} \propto L^{0.20} \sim L^{0.38}
$$

The relation Eq. (19) shows that rupture velocity is not constant and independent of earthquake size but decreases with decreasing fault length. The value of the coefficient $k$ in the $M_{0}-L$ relation has little uncertainty. However, even if $k$ takes any value between 2.5 and 3.2, the result that rupture velocity decreases with decreasing fault length needs no correction.

The above result was obtained from the combination of the $M_{0}-f_{0}$ relation with the $M_{0}-L$ relation. We will estimate the rupture velocity of a microearthquake directly from its seismogram and investigate whether the rupture velocity of the microearthquake is smaller than that of large earthquakes or not. Here, the average rupture velocity of the microfracture accompanied with aftershocks is determined from the linear dimension of the aftershock distribution and the initial pulse width on the seismogram. In the case of the unilateral rupture on the fault in which the length is $2 \mathrm{~m}$ as mentioned in Appendix 1, the rupture velocity is obtained at about 
$600 \mathrm{~m} / \mathrm{s}$ with the equation $V_{\mathrm{r}}=L / t_{\mathrm{p}}$. In the case of a circular fault whose diameter is $1 \mathrm{~m}$, the rupture velocity is obtained at about $150 \mathrm{~m} / \mathrm{s}$ with the equation $V_{\mathrm{r}}=L / 2 t_{\mathrm{p}}$. These values of the rupture velocity are distinctly smaller than those of large earthquakes of 2.3 to $3.5 \mathrm{~km} / \mathrm{s}$ that are listed in GELLER (1976).

By the way, Geller (1976) indicated that almost all the rupture velocities of earthquakes whose fault length is smaller than $100 \mathrm{~km}$ range from 2.3 to $2.5 \mathrm{~km} / \mathrm{s}$, while those larger than $100 \mathrm{~km}$ are about $3.5 \mathrm{~km} / \mathrm{s}$. Larger earthquakes show a tendency to have a larger rupture velocity.

\subsection{Dynamic fault parameters}

We will investigate another dynamic fault parameter, the average slip velocity $\dot{D}$. After the circular fault model (SATO and HiRASAWA, 1973), average slip velocity is given by

$$
\dot{D}=D / 2 t_{\mathrm{p}}
$$

where $D$ is the dislocation at the center of the fault. Here, eliminating $t_{\mathrm{P}}$ by using Eqs. (18) and (20) becomes

$$
\dot{D}=D /\left(L / V_{\mathrm{r}}\right)=D V_{\mathrm{r}} / L
$$

$D$ is related to $M_{0}$ and $L$ as

$$
D \propto M_{0} / L^{2}
$$

By using the relation $M_{0} \propto L^{2.5} \sim L^{3.2}$, replacing $M_{0}$ with $L$, the relation Eq. (22) becomes

$$
D \propto L^{0.5} \sim L^{1.2} .
$$

By Eqs. (19) and (23), replacing $D$ and $V_{\mathrm{r}}$ in Eq. (21) with $L$, the relation between $\dot{D}$ and $L$ is given by

$$
\dot{D} \propto L^{-0.12} \sim L^{0.40} .
$$

Although this relation also has a little uncertainty, this indicates that average slip velocity has a tendency to decrease with decreasing fault length.

From the results obtained above, we conclude that the values of the dynamic fault parameters decrease with decreasing fault length. This is the reason why the frequencies of microearthquakes to small earthquakes are lower than those derived from the cube law and why their deviations from the cube law increase with the decreasing seismic moment.

\section{Discussion}

\subsection{Stress condition on the fault}

5.1.1 Apparent stress

By analyzing seismograms of earthquakes of which $10^{10}<M_{0}<10^{25}$ dyne $\cdot \mathrm{cm}$, 
we have concluded that corner frequencies of small earthquakes are lower than those derived from the cube law and that the deviations from the cube law increase with decreasing earthquake size. Furthermore, it was shown that this result cannot be explained by the difference in stress drop between large and small earthquakes but by the difference in rupture velocity.

In this section, we will discuss why average rupture velocity decreases with decreasing earthquake size. The conclusion is mentioned in advance, in that small rupture velocity prevents an earthquake from growing to be larger.

The discussion was begun by the investigation of the difference in stress condition between larger and smaller earthquakes used in this paper. As mentioned above, the stress drop of earthquakes analyzed in this paper is almost constant and is independent of earthquake size. We will investigate the apparent stress of earthquakes analyzed in this paper. Apparent stress is defined as

$$
\sigma_{\mathrm{A}}=\mu E / M_{0}
$$

(AKI, 1966), where $E$ is the total radiated energy and $\mu$ is the shear modulus. As shown in Appendix 2, we assume that $E_{\mathrm{t}}=E+E_{\mathrm{f}}$, where $E_{\mathrm{t}}$ is the total released strain energy and $E_{\mathrm{f}}$ is the work dissipated in friction. Then, apparent stress is given by

$$
\sigma_{\mathrm{A}}=\left(\sigma_{0}+\sigma_{1}\right) / 2-\sigma_{\mathrm{f}}
$$

where $\sigma_{0}, \sigma_{1}$, and $\sigma_{\mathrm{f}}$ is the initial, final and frictional stress, respectively. Moreover, if we assume that $\sigma_{1}=\sigma_{\mathrm{f}}$ following OROWAN (1960), Eq. (26) becomes

$$
\sigma_{\mathrm{A}}=\Delta \sigma / 2 \text {. }
$$

This equation implies that apparent stress is constant and independent of earthquake size when stress drop is also constant and independent of earthquake size and that both apparent stress and stress drop have the same order of magnitude.

However, we find that the apparent stresses of earthquakes analyzed in this paper decrease with decreasing earthquake size. The total radiated energy $E$ is defined as $E=E_{\mathrm{P}}+E_{\mathrm{S}}$, where $E_{\mathrm{P}} \propto t_{\mathrm{P}}{ }^{5}$ and $E_{\mathrm{S}} \propto t_{\mathrm{S}}^{5}$ as shown in the above sections. Since the relation $t_{\mathrm{p}} \propto t_{\mathrm{S}}$ is generally accepted, $E_{\mathrm{S}}$ is written by $E_{\mathrm{S}} \propto t_{\mathrm{P}}{ }^{5}$. Consequently, we obtain the relation

$$
E \propto t_{\mathrm{P}}^{5}
$$

By using Eqs. (14), (25), and (28), $\sigma_{\mathrm{A}}$ is related to $t_{\mathrm{P}}$ as

$$
\sigma_{\mathrm{A}} \propto t_{\mathrm{P}}
$$

This relation indicates that apparent stress decreases with decreasing earthquake size.

The apparent stresses of earthquakes analyzed in this paper calculated by Eq. (25) are listed in Table 3. The apparent stresses of the aftershocks of the Nihonkaichubu earthquake range mainly from about 5 to 50 bars, while those of the 
microfractures induced by an explosion range mainly from 0.01 to 0.1 bar. For the small aftershocks of the Nihonkai-chubu earthquake, IwATA (1984) showed that the apparent stresses have a tendency to decrease with decreasing earthquake size. Furthermore, the apparent stresses of the aftershocks of the Nihonkai-chubu earthquake are half of the stress drops of large earthquakes of 10 to 100 bars (KANAMORI and ANDERSON, 1975), while the apparent stresses of the microfractures induced by an explosion are smaller than their stress drops by a few orders.

\subsubsection{Frictional stress}

If frictional stress holds constant during almost all the time of faulting and apparent stress is much smaller than stress drop and is almost zero, frictional stress is given by

$$
\sigma_{\mathrm{f}} \simeq\left(\sigma_{0}+\sigma_{1}\right) / 2
$$

Replacing $\sigma_{0}$ with $\Delta \sigma$ by using the well known equation $\Delta \sigma=\sigma_{0}-\sigma_{1}$, Eq. (30) becomes $\sigma_{1}=\sigma_{\mathrm{f}}-\Delta \sigma / 2$. This equation indicates that final stress is smaller than constant frictional stress by $\Delta \sigma / 2$. However, it cannot be accepted that final stress is much smaller than frictional stress. We infer from the above that for smaller earthquakes, frictional stress does not remain constant during almost all of the time of faulting but its value changes with the progress of faulting.

Figure 17 a demonstrates the probable change of frictional stress against dislocation. That can explain small apparent stress. $\sigma_{\mathrm{f}}$ decreases almost linearly from $\sigma_{0}$ to $\sigma_{1}$ with advancing dislocation. In this dependence of $\sigma_{\mathrm{f}}$ on $D$, the frictional energy is calculated as $E_{\mathrm{f}} \simeq(1 / 2)\left(\sigma_{0}+\sigma_{1}\right) D S$ by using the equation that relates stress to work $E_{\mathrm{f}}=\int^{D} \sigma_{\mathrm{f}}(D) S \mathrm{~d} D$, where $S$ is the fault area. Since $E_{\mathrm{f}}$ is nearly as large as $E_{\mathrm{t}}$, the radiated energy is very small. Consequently, the apparent stress is much smaller than the stress drop in the dependence of $\sigma_{\mathrm{f}}$ on $D$ shown in Fig. $17 \mathrm{a}$.

On the other hand, for larger earthquakes, $\sigma_{\mathrm{A}}$ is nearly as large as $\Delta \sigma$. This is explained by constant frictional stress during almost all the time of faulting as mentioned above. Figure $17 \mathrm{~b}$ demonstrates the dependence of $\sigma_{\mathrm{f}}$ on $D$ for larger earthquakes. $\sigma_{\mathrm{f}}$ decreases rapidly right after the beginning of faulting and becomes constant.

By the way, $\sigma_{\mathrm{f}}$ is defined as $\sigma_{\mathrm{f}}=\mu_{\mathrm{k}} \sigma_{\mathrm{n}}$ where $\mu_{\mathrm{k}}$ is the coefficient of kinetic friction. Since $\sigma_{\mathrm{n}}$ is constant during the faulting, the dependence of $\sigma_{\mathrm{f}}$ on $D$ is attributed to $\mu_{\mathrm{k}}$. Therefore, we find that for smaller earthquakes, $\mu_{\mathrm{k}}$ decreases gradually during the faulting, while, for larger ones, $\mu_{\mathrm{k}}$ decreases rapidly right after the beginning of faulting and becomes constant. On the other hand, in the frictional experiment on silicate rocks, SCHOLZ and ENGELDER (1976) and DIETRICH (1978) showed that $\mu_{\mathrm{k}}$ decreases with increasing slip velocity. We infer from the results of these frictional experiments that the changes of $\sigma_{\mathrm{f}}$ as described above are due to the dependence of $\mu_{\mathrm{k}}$ on slip velocity. Furthermore, we consider that the difference in the changes of $\sigma_{\mathrm{f}}$ between larger and smaller earthquakes results from the difference of the slip velocities between larger and smaller ones. By the way, we believe that the rupture initiates at the weakest point on the fault. Consequently, at the starting 

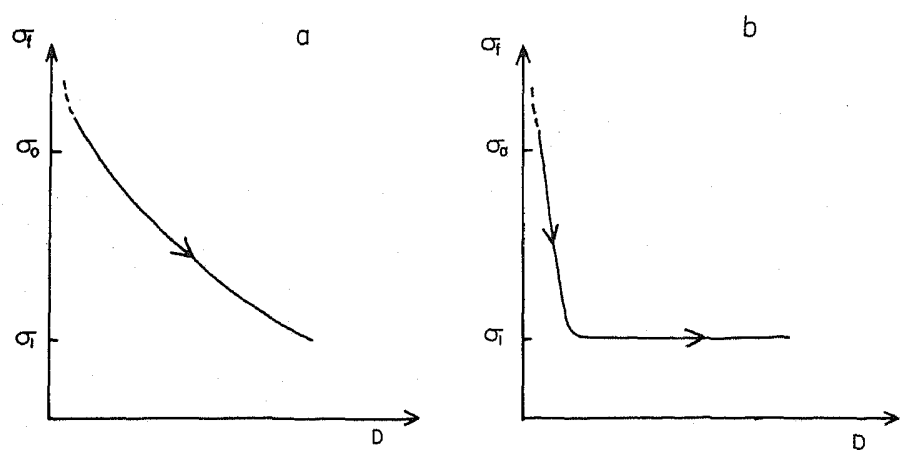

Fig. 17. Change of frictional stress against dislocation during the faulting for small earthquakes (a) and large earthquakes (b). $\sigma_{0}$ and $\sigma_{1}$ are the initial and final stress, respectively.

point of rupture, $\mu_{\mathrm{k}}$ is calculated as $\sigma_{0} / \sigma_{\mathrm{n}}$ at the moment of the onset of rupture, while at other points on the fault, $\mu_{\mathrm{k}}$ is most likely larger than $\sigma_{0} / \sigma_{\mathrm{n}}$ at the moment of the passage of the rupture front.

\subsection{Faulting mechanism}

As a result of the above discussion, the two extreme cases of faulting mechanisms are described as follows.

First, we discuss the faulting mechanism in which the rupture velocity right after the beginning of the dislocation is small. From the approximate representation of the average slip velocity by KANAMORI (1972)

$$
\dot{D}=\left(\sigma_{\mathrm{e}} V_{\mathrm{S}} / \mu\right) /\left(1+V_{\mathrm{S}} / V_{\mathrm{r}}\right)
$$

where $\sigma_{\mathrm{e}}$ is the effective stress defined as $\sigma_{\mathrm{e}}=\sigma_{0}-\sigma_{\mathrm{f}}$, we infer that the small rupture velocity causes the small slip velocity. Since the slip velocity right after the beginning of the dislocation is small, $\mu_{\mathrm{k}}$ scarcely decreases from the value of $\sigma_{0} / \sigma_{\mathrm{n}} . \sigma_{\mathrm{e}}$ remains small right after the beginning of dislocation. Consequently, the dislocation cannot be accelerated rapidly and the slip velocity only gradually increases. $\mu_{\mathbf{k}}$ decreases gradually during the faulting. The rupture velocity also cannot be accelerated. In this case, since the dislocation progresses slowly near the rupture front, the stress concentration on the rupture front is very likely small. Consequently, when the rupture front reaches the region of high strength, the probability that the rupture propagation will be stopped is very high. It is difficult that the fracture grows to be larger. When the rupture velocity right after the beginning of the dislocation is small, the fracture results in a small earthquake.

Second, we discussed the other faulting mechanism in which the rupture velocity right after the beginning of dislocation is large. The slip velocity is large and $\mu_{\mathrm{k}}$ decreases rapidly, right after the beginning of dislocation. The effective stress is also large and the dislocation accelerates smoothly. Since the stress concentration 
on the rupture front is large, the probability that the rupture propagation will be stopped is low and the fracture more than likely grows to be larger. When the rupture velocity right after the beginning of dislocation is large, the fracture grows to be an large earthquake.

For large earthquakes, after the frictional stress decreases rapidly, it becomes constant, because $\mu_{\mathrm{k}}$ does not decrease infinitely with increasing slip velocity but becomes constant when slip velocity becomes larger than the critical value (DIETRICH, 1978). Table 3 shows the apparent stress for the earthquakes in which $M=4 \sim 5$ is between about 5 to 50 bars. It is likely that almost half of the stress drops in those earthquakes. This may suggest that the slip velocity of the earthquakes $(M=4 \sim 5)$ is equal to this critical slip velocity.

The scaling relation described in this paper holds for the earthquakes of which $10^{10}<M_{0}<10^{25}$ dyne $\cdot \mathrm{cm}$. For large earthquakes of which $M_{0}>10^{25} \mathrm{dyne} \cdot \mathrm{cm}$, the cube law is generally accepted (e.g., KANAMORI and ANDERSON, 1975). This is possible because, for large earthquakes, the slip velocity exceeds the critical slip velocity and the average effective stress is constantly independent of the seismic moment.

For earthquakes in which $M_{0}<10^{10}$ dyne $\cdot \mathrm{cm}$, the scaling relation described in this paper is expected to remain good, though we have not been able to detect them until now. However, in rock experiments, we can observe acoustic emissions (AE) in which $M_{0}$ is much smaller than $10^{10}$ dyne $\cdot \mathrm{cm}$. Since $\mathrm{AE}$ is not generated by natural stress, $\mathrm{AE}$ was not used in the scaling in this paper.

Iro (1982) showed that the cube law almost holds for AE. The initial stress which generates $\mathrm{AE}$ is probably much larger than that of earthquakes. Since the dislocation of $\mathrm{AE}$ is possibly accelerated rapidly, the cube law may apparently hold for AE. In rock samples, the fracture strength is also very high. Since the rupture propagation is easily stopped by the region where there is high fracture strength, the fracture may result in a microcrack.

\section{Conclusion}

By analyzing the seismograms of earthquakes of which $10^{10}<M_{0}<10^{25}$ dyne $\cdot \mathrm{cm}$, the following conclusions are reached.

1) Radiated energy of the $P$ and $S$ wave are proportional to the fifth power of the period of $\mathrm{P}$ and $\mathrm{S}$ wave velocity seismograms.

2) Seismic moment is inversely proportional to the fourth power of the corner frequency of the $\mathrm{P}$ wave.

3) Seismic moment is proportional to the 2.5th to 3.2th power of fault length.

4) Average rupture velocity and slip velocity decrease with decreasing earthquake size.

By unifying these result, the scaling model of the earthquakes of which $10^{10}<M_{0}<10^{25}$ dyne $\cdot \mathrm{cm}$ is constructed is as follows. The similarity law holds true between static fault parameters. Dynamic fault parameters decrease with decreasing 
earthquake size. Therefore, the waveform of small earthquakes is characterized by lower frequency than that derived from the cube law $M_{0} \propto f_{0}^{-3}$.

I am grateful to Dr. Yasuhiro Umeda who made many valuable suggestions and critically reviewed the manuscript. I thank Mr. Hideo Yukutake who led me to the observation of the microfracture in the mine. I am indebted to Professor Haruo Miki and Dr. Hikaru Watanabe for reading the manuscript. I thank Dr. Rick Schult who critically reviewed the manuscript.

\section{APPENDIX}

\section{The Microfracture Accompanied with Aftershocks}

We will calculate the $E_{\mathrm{P}}, E_{\mathrm{S}}$, and $M_{0}$ of the microfracture accompanied by aftershocks. The seismograms of all the observation points were clipped (IIO, $1984 \mathrm{~b}$ ). However, the pulse widths of the first half cycle of $\mathbf{P}$ wave seismograms of all the observation points are nearly equal. Furthermore, they are almost half of the period of the coda wave. Thus, the pulse width of the first half cycle of $P$ waves is shown to be identical to that of ground motion. Moreover, the recorded waveforms exactly show part of the ground motion. Therefore, the ground motion of the first half cycle of $\mathrm{P}$ wave was inferred from extrapolating the recorded waveform as shown in Fig. A1. By measuring $A_{\mathrm{P}}$ and $t_{\mathrm{P}}$ on this waveform, $E_{\mathrm{P}}$ was calculated by Eq. (2). This estimate of $A_{\mathrm{P}}$ is accurate to a factor of 2 . When the same method was applied to the Nagano aftershocks which were almost as large as the microfracture accompanied with aftershocks, errors in the estimate of $A_{\mathrm{p}}$ were less than plus or minus $50 \%$. Moreover, as shown in Fig. 13, the first cycle of $\mathrm{P}$ wave velocity seismograms used in this study is well modeled as the extrapolating waveform in Fig. A1. $M_{0}$ was calculated by Eq. (6) using the long period flat level of the analytical Fourier transform of this waveform. The results for all the observation points are listed in Table 5.

$E_{\mathrm{S}}$ was obtained by analyzing the coda wave. Figure $\mathrm{A} 2$ shows the attenuation

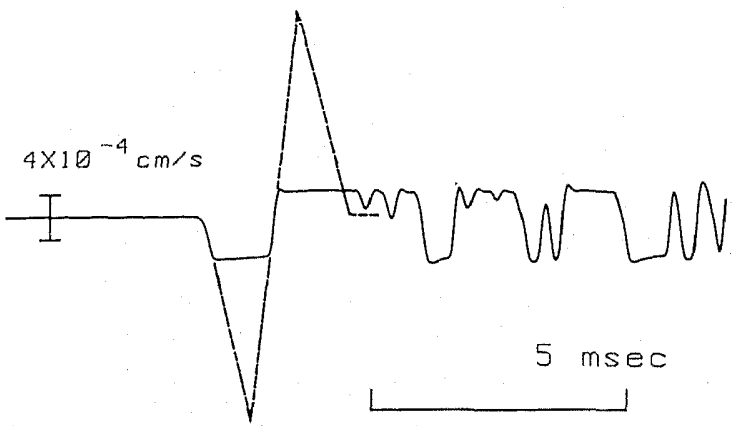

Fig. Al. The estimate of ground motion from the clipping seismogram of the microfracture accompanied with aftershocks. 


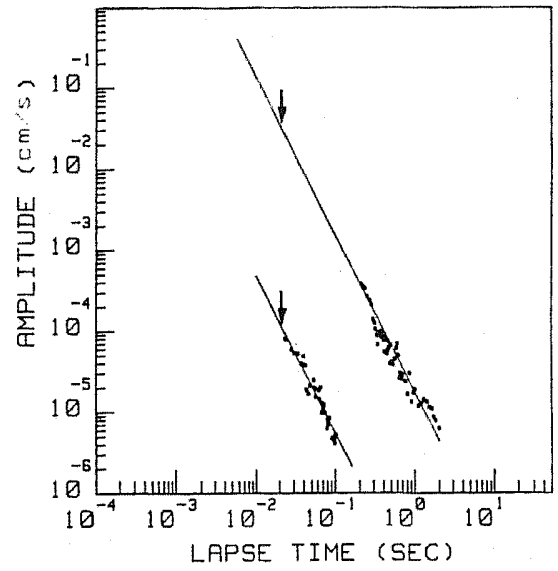

Fig. A2. Attenuation of double velocity amplitude of coda wave for the microfracture accompanied with aftershocks and the largest aftershock of it. The straight lines are computed using the least square program. Arrows indicate the time of the onset of $\mathrm{S}$ waves.

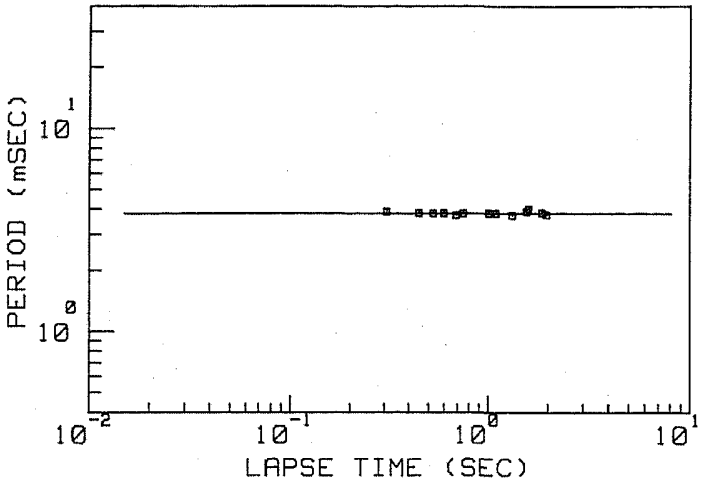

Fig. A3. Period of coda wave versus lapse time for the microfracture accompanied with aftershocks.

of the coda wave with the microfracture accompanied with aftershocks. The attenuation curve was computed using a least square program. The double amplitude at the lapse time of S-arrival indicated by an arrow was regarded as $A_{\mathrm{S}}$. In comparison, the attenuation of the coda wave of the largest aftershock is also drawn in Fig. A2; We find the double amplitude at the $\mathrm{S}$ arrival for the largest aftershock is smaller than the maximum one by about $30 \%$. The estimate of $A_{\mathrm{S}}$ of the main shock is likely accurate to plus or minus $30 \%$ also. $t_{\mathrm{S}}$ was also estimated from the coda wave. Figure A3 shows the relationship between the period of coda wave and lapse time. We find that the period of coda wave has a constant value independent of lapse time. $t_{\mathrm{S}}$ was set to this value. $E_{\mathrm{S}}$ was calculated by Eq. (5) using these value.

Next, we will investigate the fault length and stress drop of the microfracture 


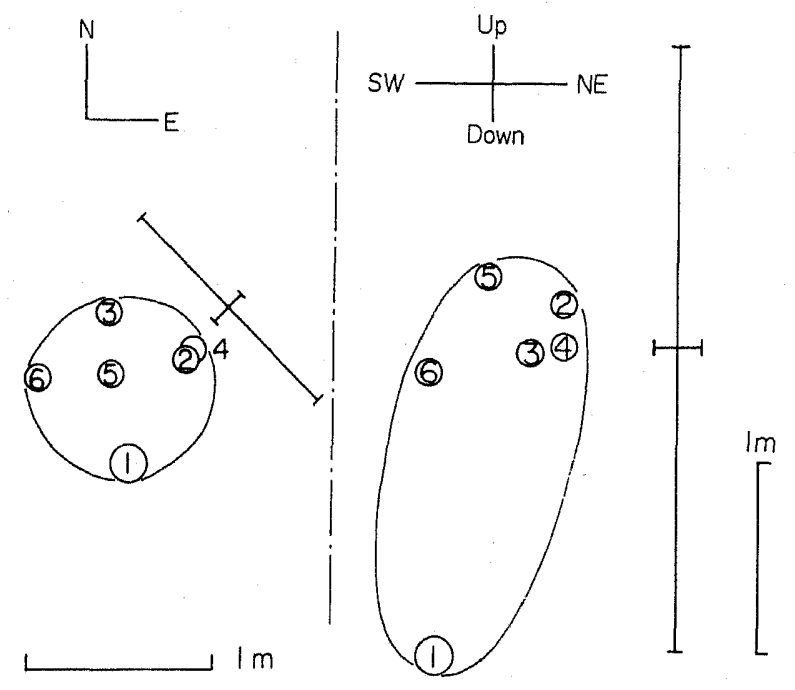

Fig. A4. The aftershock distribution of the microfracture accompanied with aftershocks, projected on the horizontal plane (left-hand side) and the vertical plane (right-hand side) after IIo (1984 b). Bars indicate the errors in hypocentral determination estimated by IIo (1984 b).

accompanied with aftershocks. The aftershock distribution of this microfracture determined by IIo (1984 b) is shown in Fig. A4. Ino (1984 b) considered the error in hypocentral determination by the use of error bars illustrated in this figure. Iro (1984 b) mentioned that only the distribution along the NE-SW direction in the plane view indicates the exact distribution and that the linear dimension of the aftershock area is about $1 \mathrm{~m}$. By the way, it is inferred from the generating mechanism of the microfractures in the Nakatatsu mine (IIO, 1984 a, b) that the dip angle of the fault of microfractures is near $90^{\circ}$. Furthermore, in the vertical section of the aftershock distribution, the hypocenters, except for the main shock, are concentrated in the small region. The error in hypocentral determination is possibly smaller than what the error bars show in Fig. A4. The region surrounded by an ellipse in the vertical section possibly indicates the fault plane of the microfracture accompanied with aftershocks. In this case, the rupture seems to begin at the hypocenter of the main shock and to propagate upward. Thus, the fault length is regarded as about 1 to $2 \mathrm{~m}$. The stress drop calculated by Eq. (10) is 250 to 2,000 bars for the fault length of 1 to $2 \mathrm{~m}$, respectively. These values of the stress drop are larger than that known for large earthquakes.

\section{Relation between $E, M_{0}, \Delta \sigma$, and $\sigma_{A}$}

During earthquake faulting, the total released strain energy $E_{\mathrm{t}}$ is partitioned in the manner (SIBSON, 1977), 


$$
E_{\mathrm{t}}=E+E_{\mathrm{f}}+E_{\mathrm{c}}+E_{\mathrm{g}},
$$

where $E$ is the total radiated energy, $E_{\mathrm{c}}$ is the fracture energy and $E_{\mathrm{g}}$ is the work done against gravity. First, we disregard $E_{\mathrm{c}}$ and $E_{\mathrm{g}}$ following SiBson (1977). Then, $E_{\mathrm{t}}$ and $E_{\mathrm{f}}$ are written as $E_{\mathrm{t}}=(1 / 2)\left(\sigma_{0}+\sigma_{1}\right) D S$ and $E_{\mathrm{f}}=\sigma_{\mathrm{f}} D S . E$ is given by the equation $E=\sigma_{\mathrm{A}} M_{0} / \mu$ which defines $\sigma_{\mathrm{A}}$ (AKI, 1966). Then, Eq. (A.1) becomes $\sigma_{\mathrm{A}}=\left(\sigma_{0}+\sigma_{1}\right) / 2-\sigma_{\mathrm{f}}$. If it is assumed $\sigma_{1}=\sigma_{\mathrm{f}}$ following OROWAN (1960), Eq. (26) becomes $\sigma_{\mathrm{A}}=\Delta \sigma / 2$.

$E_{\mathrm{c}}$ is disregarded in the above. Here, we will investigate the effect of $E_{\mathrm{c}}$ on earthquake faulting. However, estimates of $E_{\mathrm{c}}$ are uncertain. HussernI et al. (1975) evaluated the fracture energy as

$$
\gamma_{0}=r \Delta \sigma^{2} / 2 \mu \pi
$$

where $\gamma_{0}$ is the fracture energy per unit length along the fault edge per unit extension of rupture and $r$ is the fault radius. $E_{\mathrm{c}}$ is calculated by the integral calculus of Eq. (A.2) over the fault surface as follows

$$
E_{\mathrm{c}}=\Delta \sigma^{2} r^{3} / 3 \mu \text {. }
$$

Dividing by $M_{0} /$ using Eqs. (10) and (A.3) becomes

$$
E_{\mathrm{c}} /\left(M_{0} / \mu\right)=(7 / 48) \Delta \sigma \text {. }
$$

If $E_{\mathrm{c}}$ is not disregarded, Eq. (A.1) becomes

$$
\sigma_{\mathrm{A}}=\left(\sigma_{0}+\sigma_{1}\right) / 2-\sigma_{\mathrm{f}}-(7 / 48) \Delta \sigma .
$$

From this equation, we find that $\sigma_{\mathrm{A}}$ is slightly lowered by the effect of $E_{\mathrm{c}}$. When $\sigma_{\mathrm{A}}$ is nearly equal to $\Delta \sigma$, the effect of $E_{\mathrm{c}}$ can be disregarded. Even if $\sigma_{\mathrm{A}}$ is nearly zero, we have disregarded this effect in the discussion of this paper. The reason is as follows. We discuss the dependence of $\sigma_{\mathrm{A}}$ on earthquake size in this paper. Whereas, the effect of $E_{\mathrm{c}}$ is the same independent of earthquake size because $\Delta \sigma$ is constant independent of earthquake size for the earthquakes analyzed in this paper. Consequently, $E_{\mathrm{c}}$ has no effect with the dependence of $\sigma_{\mathrm{A}}$ on earthquake size. Therefore, in this paper, we disregard $E_{\mathrm{c}}$ and regard Eq. (26) as the estimate of $\sigma_{\mathrm{A}}$.

\section{Relation between Corner Frequency and Fault Radius}

Almost all the studies that investigated the relation $M_{0}$ and $f_{0}$ from spectral analyses of seismograms are based on BRUne $(1970,1971)$. BRUNE $(1970,1971)$ related corner frequency to fault radius as follows

$$
r=2.34 V_{\mathrm{S}} / 2 \pi f_{0} \text {. }
$$

On the other hand, SATO and HiRASAWA (1973) showed the relation

$$
r=C\left(V_{\mathrm{r}}\right) V_{\mathrm{S}} / 2 \pi f_{0} .
$$


Here, $C\left(V_{\mathrm{r}}\right)$ depends on rupture velocity and increases with increasing rupture velocity. Equation (A.6) is the same as Eq. (A.7) when $C\left(V_{\mathrm{r}}\right)$ is set to 2.34. Equation (A.6) by BRUNE $(1970,1971)$ remains true only when $V_{\mathrm{r}}$ takes the fixed value for which $C\left(V_{\mathrm{r}}\right)=2.34$. Therefore, we cannot use Eq. (A.6) when $V_{\mathrm{r}}$ takes another value and $V_{\mathrm{r}}$ changes with earthquake size.

\section{Relation between Seismic Moment and Magnitude}

We will investigate the relation between $M_{0}$ and the magnitude $M$. The magnitude determined by J.M.A. is used in this paper. For earthquakes of which $M$ weren't determined by J.M.A., $M$ was calculated from Watanabe's formula (WatANABE, 1971). $M_{0}$ was determined in section 3.2.1. The relation between $M_{0}$ and $M$ is shown in Fig. A5. The data plotted range very widely in $M$ from -3 to 6 and in $M_{0}$ from $10^{10}$ to $10^{25}$ dyne $\cdot \mathrm{cm}$. The data of the Nagano aftershocks are indicated by open triangles. These data slightly deviate from the trend of the other data. This may be because of the error in the determination of $M$. The straight line which represents the relation $\log M_{0}=1.37 M+16.2$ is computed using the least

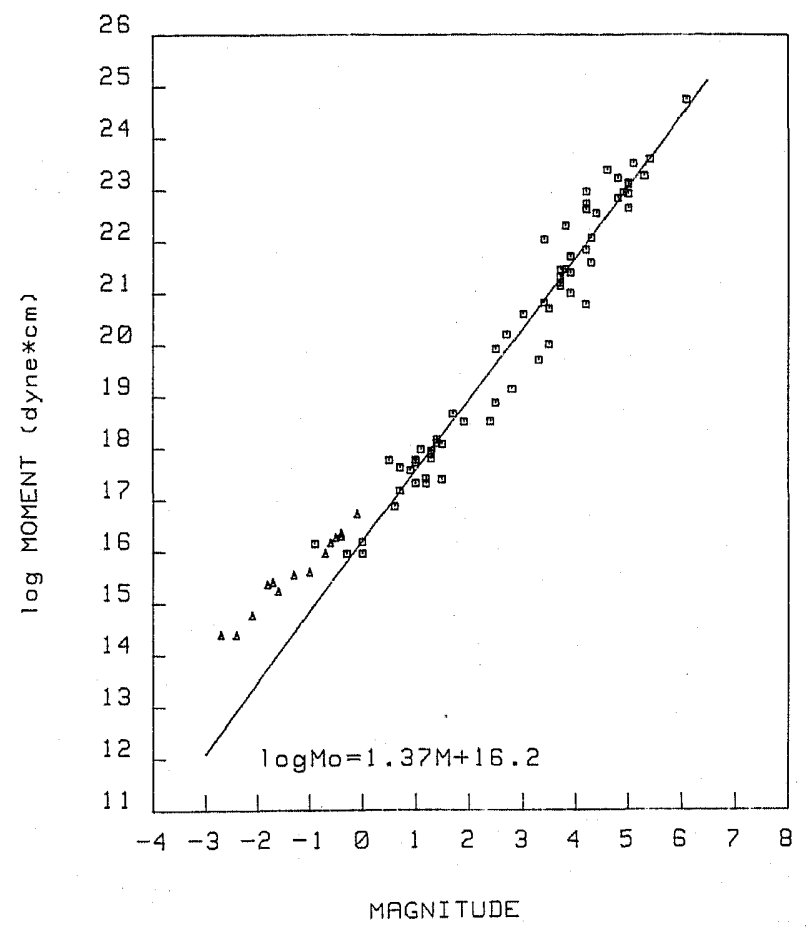

Fig. A5. Seismic moment versus magnitude. Triangles indicate the aftershocks of the 1984 Western part of Nagano Prefecture earthquake. The straight line is computed from the data, except for these aftershocks. 
square program from the data except for the Nagano aftershocks. Several equations had been reported for the $M_{0}-M$ relation (e.g., Wyss and BRUNE, 1968; THATCHER and HANKS, 1973). The coefficients of $M$ in these equations range from 1.4 to 1.5 and are slightly larger than that obtained here.

By the way, since magnitude is defined as the logarithm of the maximum amplitude of displacement seismogram at a certain focal distance, $M$ is proportional to $\log A$. From Eq. (13), $M$ is related to $t_{\mathrm{p}}$ as

$$
M \propto \log A \propto 3 \log t_{\mathrm{P}} .
$$

By Eq. (14) with $M_{0}$ replacing $t_{\mathrm{p}}$, the relation Eq. (A.8) becomes $\log M_{0} \propto 4 / 3 M$. This relation is consistent with Eq. (16). The relation $M_{0} \propto f_{0}{ }^{-4}$ is supported by the $M_{0}-M$ relation.

\section{REFERENCES}

AKI, K., Generation and propagation of $G$ waves from the Niigata earthquake of June 16, 1964. 2. Estimation of earthquake moment, released energy and stress-strain drop from G wave spectrum, Bull. Earthq. Res. Inst., Univ. Tokyo, 44, 73-88, 1966.

AkI, K., Scaling law of seismic spectrum, J. Geophys. Res., 72, 1217-1231, 1967.

AKI, K., Scaling law of earthquake source time-function, Geophys. J. R. Astron. Soc., 31, 3$25,1972$.

AKI, K. and B. CHOUET, Origin of coda waves: Source, attenuation, and scattering effects, $J$. Geophys. Res., 80, 3322-3342, 1975.

Archuleta, R. J., E. Cranswick, C. Mueller, and P. Spudich, Source parameters of the 1980 Mammoth Lakes, California, earthquake sequence, J. Geophys. Res., 87, 45954607, 1982.

Azimi, S. A., A. V. Kalinin, V. V. Kalinin, and B. L. Pivovarov, Impulse and transient characteristics of media with linear and quadratic absorption laws, Izv., Earth Phys., 1968 (2), 88-93, 1968.

BOATWRIGHT, J., A spectral theory for circular seismic sources; simple estimates of source dimension, dynamic stress drop, and radiated seismic energy, Bull. Seismol. Soc. Am., 70, 1-27, 1980.

BRUnE, J. N., Tectonic stress and the spectra of seismic shear waves from earthquakes, $J$. Geophys. Res., 75, 4997-5009, 1970.

Brune, J. N., Correction, J. Geophys. Res., 76, 5002, 1971.

Chouet, B., K. AKI, and M. TsujIURA, Regional variation of the scaling law of earthquake source spectra, Bull. Seismol. Soc. Am., 68, 49-79, 1978.

Dietrich, J. H., Time-dependent friction and the mechanics of stick-slip, Pure Appl. Geophys., 116, 790-806, 1978.

FACULTY OF SCIENCE, KYOTO UNIVERsity, Synthetic observation for the earthquake prediction at Yugashima, Rep. Coord. Comm. Earthq. Predict., 29, 143-146, 1983 (in Japanese).

Faculty of Science, Kyoto University and Disaster Prevention Research Institute, K yото University, The earthquake near Kyoto city, November 16, 1983, Rep. Caord. Cormm. Earthq. Predict., 32, 284-294, 1984 (in Japanese). 
FLETCHER, J. B., Spectra from high-dynamic range digital recordings of Oroville, California aftershocks and their source parameters, Bull. Seismol. Soc. Am., 70, 735-755, 1980.

Frankel, A., Source parameters and scaling relationships of small earthquakes in the northeastern Caribbean, Bull. Seismol. Soc. Am., 71, 1173-1 190, 1981.

Geller, R., Scaling relations for earthquake source parameters and magnitudes, Bull. Seismol. Soc. Am., 66, 1501-1523, 1976.

HAAR, L., J. B. Fletcher, and C. S. Mueller, The 1982 Enola, Arkansas, swarm and scaling of ground motion in the eastern United States, Bull. Seismol. Soc. Am., 74, 2463-2482, 1984.

HANKS, T. C., Earthquake stress drops, ambient tectonic stresses and stresses that drive plate motions, Pure Appl. Geophys., 115, 441-458, 1977.

HANKS, T. C. and M. Wyss, The use of body wave spectra in the determination of seismicsource parameters, Bull. Seismol. Soc. Am., 62, 561-589, 1972.

HARTZELL, S. H. and J. N. BRUNE, Source parameters for the January 1975 Brawley-Imperial Valley earthquake swarm, Pure Appl. Geophys., 115, 333-355, 1977.

Husseini, M. I., D. B. Jovanovich, M. J. Randall, and L. B. Freund, The fracture energy of earthquakes, Geophys. J. R. Astron. Soc., 43, 367-385, 1975.

Iro, Y., Scaling of rupture size - from earthquake to acoustic emission, Zisin (J. Seismol. Soc. Jpn.), Ser. 2, 35, 183-193, 1982 (in Japanese).

Iı, Y., Micro-fracture induced by an explosion, Zisin (J. Seismol. Soc. Jpn.), Ser. 2, 37, 109 118,1984 a (in Japanese).

Iro, Y., Micro-fracture accompanied with aftershocks, Zisin (J. Seismol. Soc. Jpn.), Ser. 2, 37, $599-606,1984$ b (in Japanese).

IIo, Y., Ultramicroearthquakes near the ground surface $(M=-3)$ aftershocks of the 1984 Western Nagano Prefecture earthquake, Program. Abstr., Seismol. Soc. Jpn., No. 1, 10, 1985 (in Japanese).

IIo, Y. and A. KUROIso, On the remarkable seismic activity near Abuyama with many felt earthquakes since Jan. 1981, Program. Abstr., Seismol. Soc. Jpn., No. 1, 23, 1981 (in Japanese).

ITo, K. and A. Kurorso, Detailed spacial distributions of foreshock and aftershock activities of small earthquakes, Zisin (J. Seismol. Soc. Jpn.), Ser. 2, 32, 317-327, 1979 (in Japanese).

IWATA, T., Apparent stress of the 1983 Mid-Japan Sea earthquake and its aftershocks, Program. Abstr., Seismol. Soc. Jpn., No. 2, 101, 1984 (in Japanese).

KANAMORI, H., Determination of effective tectonic stress associated with earthquake faulting. The Tottori earthquake of 1943, Phys. Earth Planet. Inter., 5, 426-434, 1972.

KANAMORI, H. and D. L. Anderson, Theoretical basis of some empirical relations in seismology, Bull. Seismol. Soc. Am., 65, 1073-1095, 1975.

KeILrs-BoroK, V. I., Investigation of the mechanism of earthquakes, Sov. Res. Geophys., 4, 29, 1960 (English transl.).

KURoISO, A. and H. WatANABE, On the telemetered array system for microearthquake observation at Abuyama seismological observatory, Zisin (J. Seismol. Soc. Jpn.), Ser. 2, 30, 91-106, 1977 (in Japanese).

Kuroiso, A., Y. Iro, and N. MAEDA, The earthquake at Oyamazakicho in Kyoto Pref. of May 5, 1984, Program. Abstr., Seismol. Soc. Jpn., No. 2, 78, 1984 (in Japanese).

MAEDA, N. and A. Kuroiso, The felt earthquake $(M=4.5)$ at Lake Biwa of Sep. 11, 1980, 
Program. Abstr., Seismol. Soc. Jpn., No. 1, 22, 1981 (in Japanese).

MaLION, G. E. and L. T. LONG, Microearthquake spectra in the southeastern United States, Bull. Seismol. Soc. Am., 70, 1037-1054, 1980.

Miкumo, T., Source process of deep and intermediate earthquakes as inferred from longperiod $\mathrm{P}$ and $\mathrm{S}$ waveforms 2. Deep-focus and intermediate depth earthquakes around Japan, J. Phys. Earth, 19, 303-320, 1971.

National Research Center for Disaster Prevention, The earthquake near Lake Hamana, March 16, 1983, Rep. Coord. Comm. Earthq. Predict., 30, 191-192, 1983 (in Japanese).

National Research Center for Disaster Prevention, The earthquake in the eastern part of Yamanashi Prefecture, August 8, 1983, Rep. Coord. Comm. Earthq. Predict., 31, 173179,1984 a (in Japanese).

National Research Center for Disaster Prevention, The near Lake Hamanako earthquake of November 24, 1983, Rep. Coord. Comm. Earthq. Predict., 32, 280-281, 1984 b (in Japanese).

Orowan, E., Mechanism of seismic faulting, in rock deformation, Geol. Soc. Am. Mem., 79, 323-345, 1960.

Rautian, T. G., V. I. Khalturin, V. G. Martynov, and P. Molnar, Preliminary analysis of the spectral content of $\mathrm{P}$ and $\mathrm{S}$ waves from local earthquakes in the Garm, Tadjikistan region, Bull. Seismol. Soc. Am., 68, 949-971, 1978.

Sato, T., Aftershock distribution of the 1983 Mid Japan Sea Earthquake as determined by the dipping-layered velocity model, Program. Abstr., Seismol. Soc. Jpn., No. 1, 37, 1984 (in Japanese).

Sato, T. and T. Hirasawa, Body wave spectra from propagating shear cracks, J. Phys. Earth, 21, 415-431, 1973.

SavaGE, J. C., Thermoelastic attenuation of elastic waves by cracks, J. Geophys. Res., 71, 3929-3938, 1966.

Scholz, C. H. and J. T. ENGELDER, The role of asperity identation and ploughing in rock friction 1. Asperity creep and stick-slip, Int. J. Rock Mech. Min. Sci. Geomech. Abstr., 113, 149-154, 1976.

SIBSON, R. H., Kinetic shear resistance, fluid pressure and radiation efficiency during seismic faulting, Pure Appl. Geophys., 115, 387-400, 1977.

Thatcher, W., Regional variations of seismic source parameters in the northern Baja California area, J. Geophys. Res., 77, 1549-1565, 1972.

ThATCHER, W. and T. C. HANKs, Source parameters of southern California earthquakes, $J$. Geophys. Res., 78, 8547-8576, 1973.

The Research Group for the Yamasaki FaUlt, An earthquake at the Yamasaki Fault (May 30, 1984, M 5.6), Rep. Coord. Comm. Earthq. Predict., 33, 355-382, 1985 (in Japanese).

TOtTORI MicroearthQuake ObServatory and MicroearthQuake Research Section, Disaster Prevention Research Institute, Kyoto University and Institute of EARTHSCIENCES, TOTTORI University, An earthquake (M6.2) on Oct. 31, 1983 at the central part of Tottori Pref., Rep. Coord. Comm. Earthq. Predict., 31, 390-398, 1984 (in Japanese).

TUCKER, B. E. and J. N. BRUNE, Seismograms, S-wave spectra, and source parameters for aftershocks of the San Fernando earthquake, in Geological and Geophysical Studies, Vol. 
3, San Fernando, California Earthquake of February 9, 1971, pp. 69-122, U.S. Dept. of Commerce, 1973.

Umeda, Y., Y. Iro, A. Kuroiso, K. Ito, and H. Murakami, Scaling of observed seismic spectra, Zisin (J. Seismol. Soc. Jpn.), Ser. 2, 37, 559-567, 1984 (in Japanese).

WALSH, J. B., Seismic-wave attenuation in rock due to friction, J. Geophys. Res., 71, 25912599, 1966.

WatanABE, H., Determination of earthquake magnitude at regional distance in and near Japan, Zisin (J. Seismol. Soc. Jpn.), Ser. 2, 24, 189-200, 1971 (in Japanese).

WYSS, M. and J. N. BRUNE, Seismic moment, stress, and source dimensions for earthquakes in the California-Nevada region, J. Geophys. Res., 73, 4681-4694, 1968.

Wyss, M. and J. N. BRUNE, Regional variations of source properties in southern California estimated from the ratio of short to long-period amplitudes, Bull. Seismol. Soc. Am., 61, 1153-1167, 1971. 